\title{
7.6 TROPOSPHERIC AIRBORNE METEOROLOGICAL DATA REPORTING (TAMDAR) SENSOR DEVELOPMENT
}

\author{
Taumi S. Daniels* and George Tsoucalas \\ NASA Langley Research Center, Hampton, Virginia \\ Mark Anderson and Daniel Mulally \\ AirDat, LLC, Evergreen, Colorado \\ William Moninger \\ NOAA Forecast Systems Laboratory, Boulder, Colorado \\ Richard Mamrosh \\ NOAA National Weather Service, Green Bay, Wisconsin
}

\section{INTRODUCTION}

One of the recommendations of the National Aviation Weather Program Council was to expand and institutionalize the generation, dissemination, and use of automated pilot reports (PIREPS) to the full spectrum of the aviation community, including general aviation. In response to this and other similar recommendations, NASA initiated cooperative research into the development of an electronic pilot reporting capability (Daniels 2002).

The ultimate goal is to develop a small low-cost sensor, collect useful meteorological observations below 25,000 ft., downlink the data in near real time, and use the data to improve weather forecasts. Primary users of the data include pilots, who are one targeted audience for the improved weather information that will result from the TAMDAR data. The weather data will be disseminated and used to improve aviation safety by providing pilots with enhanced weather situational awareness. In addition, the data will be used to improve the accuracy and timeliness of weather forecasts. Other users include air traffic controllers, flight service stations, and airline weather centers. Additionally, the meteorological data collected by TAMDAR is expected to have a significant positive impact on forecast accuracy for ground based applications.

A system of TAMDAR sensors and datalinks on a sufficient number of aircraft would provide high temporal- and spatial-resolution wind and temperature data in the lower troposphere. Such a system has the potential to substantially improve weather forecasting. Moreover, the high-resolution humidity data produced by TAMDAR is unprecedented, and may provide substantial benefits. The meteorological community is keenly interested in additional observations of the lower troposphere and in particular moisture data as

*Corresponding author address: Taumi Daniels, NASA Langley Research Center, MS 473, Hampton, VA 23681; email: t.s.daniels@larc.nasa.gov. evidenced by the American Meteorological Society Statement (AMS Council, 2003).

NASA is working with AirDat, LLC., of Raleigh, NC (formerly Optical Detection Systems of Rapid City, SD) to develop the sensor. AirDat has developed a few prototype sensors that were subjected to numerous tests in ground and flight facilities. As a result of these earlier tests, many design improvements were made to the sensor. The results of tests on a final version of the sensor are the subject of this report.

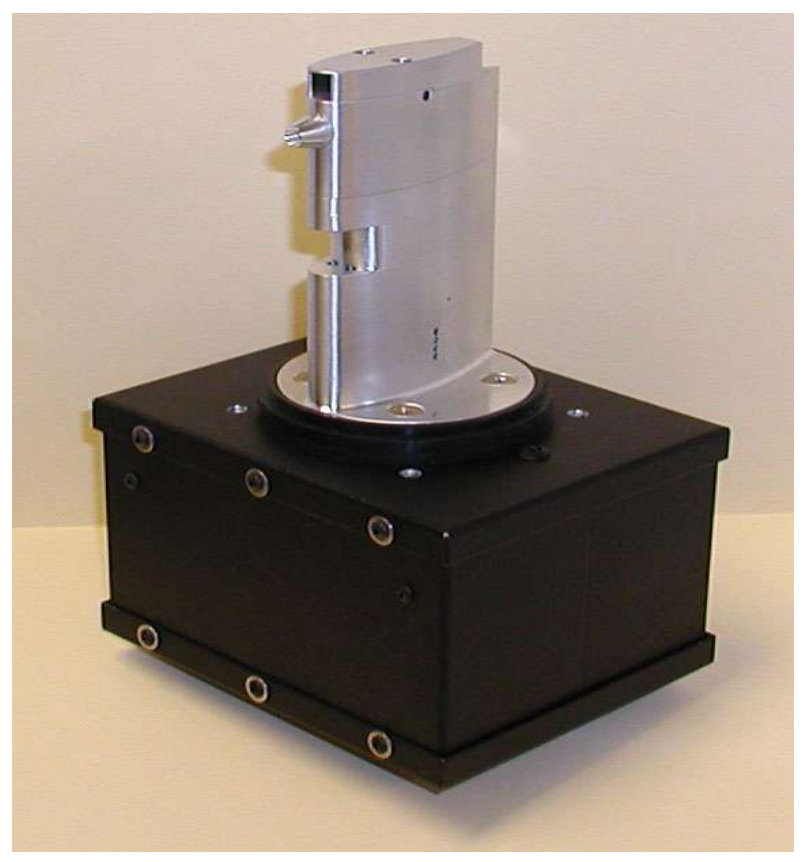

Figure 1.

TAMDAR sensor

After all the aircraft are equipped, a planned sixmonth fleet experiment will commence. This experiment will involve equipping 64 Mesaba Airlines Saab 340 aircraft with the TAMDAR sensor, collecting the data, and analyzing the impact on model and local forecasts. 


\section{SENSOR DESCRIPTION}

The sensor is capable of measuring temperature, relative humidity, pressure, and icing. It can compute pressure altitude, indicated air speed, true air speed, turbulence (MacCready, 1964), and winds. Refer to the Appendix for a mechanical schematic of the probe and a list of reported parameters.

The sensor, shown in figure 1, is configured with two capacitive humidity sensors. The temperature measurement device is a platinum RTD (resistive temperature device). Static and dynamic pressure are measured by absolute and differential pressure gauges. Two independent infrared emitter/detector pairs mounted in a leading edge recess detect ice accretion. Internal heaters melt the ice and the measurement cycle repeats. All other reported parameters are computed by processors in a signal processing unit (SPU). A GPS receiver chip is incorporated into the SPU. A separate satellite transceiver downlinks the data to a ground facility.

\subsection{Observations Intervals}

All observation intervals are based on pressure with a timed default. Departure field pressure is automatically determined at the moment the aircraft true air speed exceeds 80 knots. An observation is made every $10 \mathrm{hPa}$ for the first $100 \mathrm{hPa}$, then every $50 \mathrm{hPa}$ To avoid constant triggering of observations if the aircraft altitude is "hovering" about a particular threshold point, simple logic will be applied before a pressure based observation is triggered. Once a threshold is crossed, crossing that same threshold again will not trigger a new observation unless a higher or lower threshold is crossed first.

The time defaults for observation intervals are required in case the aircraft is in cruise (no significant change in measured ambient pressure). An observation is made after three minutes if the pressure is greater than $465 \mathrm{hPa}$ or seven minutes if the pressure is less than $465 \mathrm{hPa}$. The observation default time periods are adjustable by remote command.

Special observations are triggered by an icing onset. The minimum time between observations due to icing is 1 minute. De-icing heaters automatically remove ice from the probe upon detection. The heaters remain powered for at least 1 minute. The large electrical current flow to the probe affects the other measurements, so all data is flagged during deicing. The de-icing cycle repeats if more ice is detected.

All observation parameters pass through a firmware implemented low-pass filter with a time response of about 10 seconds with the exception of turbulence and icing. Peak and median turbulence statistics at the end of a report will apply to the total reporting interval.
Upon landing, the last ten $10 \mathrm{hPa}$ interval observations will be transmitted. The TAMDAR unit always archives the last ten observations. This assumes the default sampling interval is $10 \mathrm{hPa}$. For a $5 \mathrm{hPa}$ interval, twenty $5 \mathrm{hPa}$ spaced observations will be sent.

\subsection{Reporting Intervals}

Reports are attempted after a specific number of accumulated observations, with a report time default if a report has not been made within a certain period. The number of observations can be set by remote command. The observations are accumulated then a report is issued. If a report has not been issued for a default period of fifteen minutes, then a report is issued. The default period is adjustable by remote command. After a report has been issued, the time is reset and the next report occurs when the next set of observations have been accumulated, or at the end of the default period, whichever comes first.

These observation and reporting intervals are consistent with World Meteorological Organization AMDAR (Aircraft Meteorological Data Relay) specifications (WMO 2003).

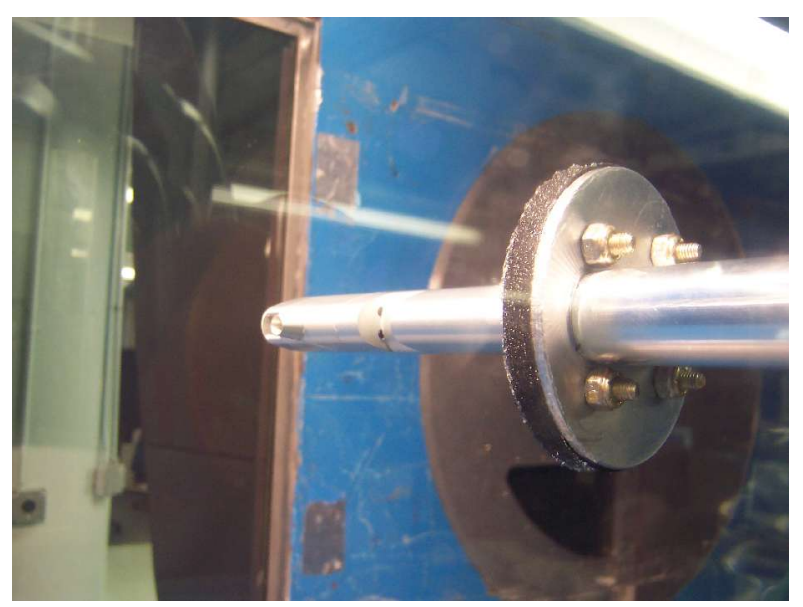

Figure 2. TAMDAR at the Cox Icing Wind Tunnel

\section{GROUND-BASED SENSOR TESTING}

The TAMDAR sensor was designed to meet the specifications in Appendix B. Various ground-based and flight tests have been conducted to verify performance. Wind tunnels, environmental chambers, and different atmospheric research aircraft have been utilized to improve the sensor performance. In addition, computational fluid dynamics (CFD) studies were conducted to determine optimum locations for pressure ports and nozzle shapes. 


\begin{tabular}{|l|l|l|l|}
\hline Parameter & Condition 1 (rime) & Condition 2 (glaze) & Condition 3 (rime) \\
\hline Water Concentration & $0.5 \pm 0.05 \mathrm{~g} / \mathrm{m}^{3}$ & $0.75 \pm 0.08 \mathrm{~g} / \mathrm{m}^{3}$ & $1.0 \pm 0.1 \mathrm{~g} / \mathrm{m}^{3}$ \\
\hline $\begin{array}{l}\text { Ambient } \\
\text { Temperature }\end{array}$ & $-20 \pm 2^{\circ} \mathrm{C}$ & $-3 \pm 2^{\circ} \mathrm{C}$ & $-30 \pm 2^{\circ} \mathrm{C}$ \\
\hline True Airspeed & $120 \pm 10$ knots & $145 \pm 10$ knots & $200 \pm 10$ knots \\
\hline Water droplet MVD & $15 \pm 10 \mathrm{E}-6$ meters & $40 \pm 10 \mathrm{E}-6$ meters & $20 \pm 10 \mathrm{E}-6$ meters \\
\hline Response time & less than 120 seconds & less than 90 seconds & less than 20 seconds \\
\hline
\end{tabular}

Table 1: $\quad$ Icing Wind Tunnel Test Conditions

\subsection{Icing Wind Tunnel Testing}

The TAMDAR sensor was tested at the LeClerc Icing Research Laboratory in New York City, New York on December, 2003. The TAMDAR sensor is shown undergoing testing in this wind tunnel in figure 2.

The objective was to test the ice detection capabilities of the TAMDAR sensor under the three conditions specified in Table 1. These sets of conditions are specified in the EUROCAE document "Minimum Operational Performance Specification for In-Flight Icing Detection Systems" which is an FAA approved guideline for aircraft ice detection. The guideline specifies that ice be successfully detected within the response time under each of the conditions listed below.

\begin{tabular}{|r|l|l|l|l|}
\hline Condition & Pitch & Yaw & $\begin{array}{l}\text { TAMDAR } \\
\text { sensor } \\
\text { Response } \\
\text { Time }\end{array}$ & $\begin{array}{l}\text { Required } \\
\text { Response } \\
\text { Time }\end{array}$ \\
\hline 1 & $-10^{\circ}$ & $0^{\circ}$ & $30 \mathrm{sec}$ & $120 \mathrm{sec}$ \\
\hline 1 & $-10^{\circ}$ & $-5^{\circ}$ & $24 \mathrm{sec}$ & $120 \mathrm{sec}$ \\
\hline 1 & $-10^{\circ}$ & $-10^{\circ}$ & $24 \mathrm{sec}$ & $120 \mathrm{sec}$ \\
\hline 1 & $0^{\circ}$ & $0^{\circ}$ & $21 \mathrm{sec}$ & $120 \mathrm{sec}$ \\
\hline 1 & $0^{\circ}$ & $-5^{\circ}$ & $21 \mathrm{sec}$ & $120 \mathrm{sec}$ \\
\hline 1 & $0^{\circ}$ & $-10^{\circ}$ & $36 \mathrm{sec}$ & $120 \mathrm{sec}$ \\
\hline 2 & $-10^{\circ}$ & $0^{\circ}$ & $20 \mathrm{sec}$ & $90 \mathrm{sec}$ \\
\hline 2 & $-10^{\circ}$ & $-5^{\circ}$ & $18 \mathrm{sec}$ & $90 \mathrm{sec}$ \\
\hline 2 & $-10^{\circ}$ & $-10^{\circ}$ & $18 \mathrm{sec}$ & $90 \mathrm{sec}$ \\
\hline 2 & $0^{\circ}$ & $0^{\circ}$ & $18 \mathrm{sec}$ & $90 \mathrm{sec}$ \\
\hline 2 & $0^{\circ}$ & $-5^{\circ}$ & $18 \mathrm{sec}$ & $90 \mathrm{sec}$ \\
\hline 2 & $0^{\circ}$ & $-10^{\circ}$ & $22 \mathrm{sec}$ & $90 \mathrm{sec}$ \\
\hline 3 & $0^{\circ}$ & $-5^{\circ}$ & $15 \mathrm{sec}$ & $20 \mathrm{sec}$ \\
\hline 3 & $0^{\circ}$ & $-10^{\circ}$ & $18 \mathrm{sec}$ & $20 \mathrm{sec}$ \\
\hline 3 & $0^{\circ}$ & $0^{\circ}$ & $18 \mathrm{sec}$ & $20 \mathrm{sec}$ \\
\hline 3 & $-10^{\circ}$ & $-5^{\circ}$ & $15 \mathrm{sec}$ & $20 \mathrm{sec}$ \\
\hline 3 & $-10^{\circ}$ & $-10^{\circ}$ & $15 \mathrm{sec}$ & $20 \mathrm{sec}$ \\
\hline 3 & $-10^{\circ}$ & $0^{\circ}$ & $15 \mathrm{sec}$ & $20 \mathrm{sec}$ \\
\hline
\end{tabular}

Table 2: Ice detection response time

Due to the wind tunnel's operational limitations the water concentration was changed from $0.3 \mathrm{~g} / \mathrm{m}^{3}$ to 0.5 $\mathrm{g} / \mathrm{m}^{3}$ for Condition 1 and the airspeed was changed from 250 knots to 200 knots for Condition 3. Additionally, each of the three conditions specified in the Table were tested with roll set at $0^{\circ}$ for all angular configurations.

The response time is measured as the time the sensor detects ice minus the time the spray (water dispersion) starts. As shown in Table 2, the TAMDAR sensor detected ice under all required conditions and at all angle configurations well within the required response times.

\subsection{Wind Tunnel Studies}

In addition to the LeClerc icing wind tunnel, the TAMDAR sensor was tested in the University of North Dakota School of Aerospace Wind Tunnel on November 2003 as shown in Figure 3. Several prototype probes were fabricated and tested. Of interest was a mechanical design modification to correct for pressure errors seen in the flight test data. The TAMDAR probe was redesigned to optimize locations of static pressure ports and of liquid water drain holes. In addition, pitot nozzle variations were also tested.

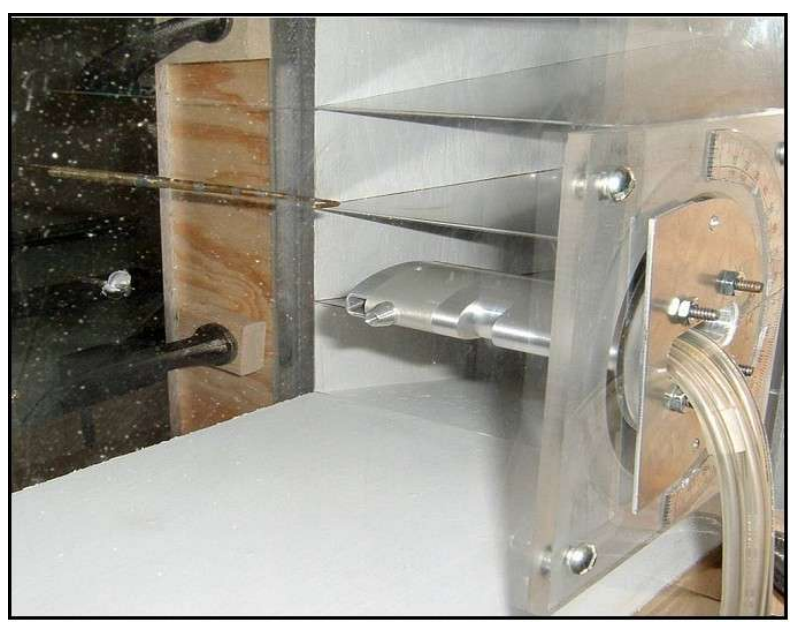

Figure 3. TAMDAR in the UND Wind Tunnel

In one series of tests, water with a blue green dye was pumped through a prototype sensor body and into the air inlet above the pitot port to verify that the internal chamber remained free of liquid water. These tests were conducted at a range of yaw angles and 
airspeeds. The internal chamber houses the PC board with the $\mathrm{RH}$ sensors.

The goal of another series of tests was to optimize the probe tip design to be independent of flow angle. The plot shown in Figure 4 is a result of the nozzle tests conducted in this wind tunnel. Total pressure recovery as a function of probe angle at flow speeds of $48 \mathrm{~m} / \mathrm{s}$ and $75 \mathrm{~m} / \mathrm{s}$. Various probe dynamic pressure tips were tested over a range of off-axis flow angles. The performance of the TAMDAR sensor is shown to be consistent to $10^{\circ}$ pitch (or yaw flow) angle.

The TAMDAR sensor was also tested at the Rolls Royce wind tunnel facility at transonic velocities up to Mach 0.9. This testing was conducted to verify the functionality of the sensor on higher performance aircraft (such as regional jets), and to refine TAMDAR algorithms for accuracy at higher velocities. Preliminary results from the tests demonstrated the suitability of the TAMDAR sensor for high performance aircraft.

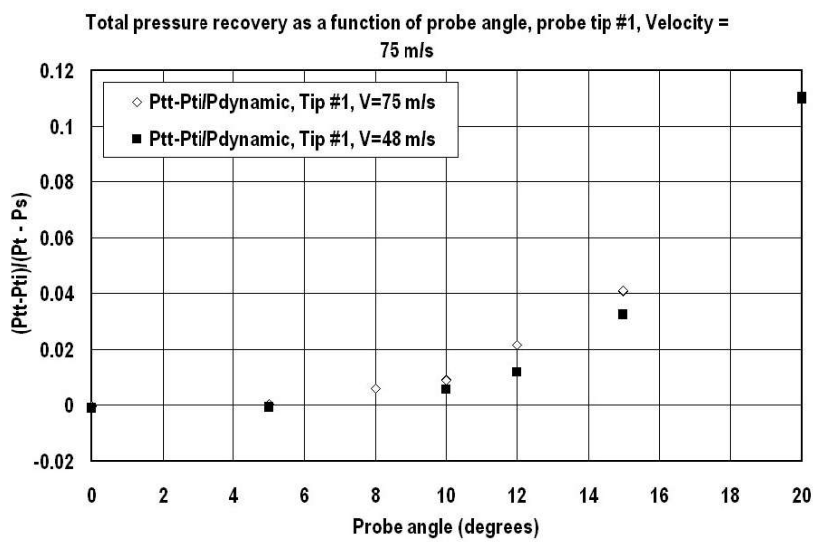

Figure 4. Effect of Probe Angle Variation on Total Pressure Recovery

\subsection{Computational Fluid Dynamics Analyses}

Several CFD simulations were performed on the TAMDAR sensor. The TAMDAR geometry was recreated based on mechanical drawings. A control volume was created that measured $25 \times 25 \times 70$ inches and that allowed for pitch and yaw simulations. The sensor was attached to the top of the control volume, with its central axis located 20 inches downstream of the flow inlet. This orientation matches that of underfuselage or under-wing aircraft installations.

The TAMDAR simulations were set up to emulate a wind tunnel. At the flow inlet, a uniform velocity boundary condition was set up normal to the face, and this value was varied in order to test the different velocities. At the outlet, the valid assumption was made for fully compressible flows and low subsonic compressible flows. For all interior walls of the control volume, a slip boundary condition was assigned.

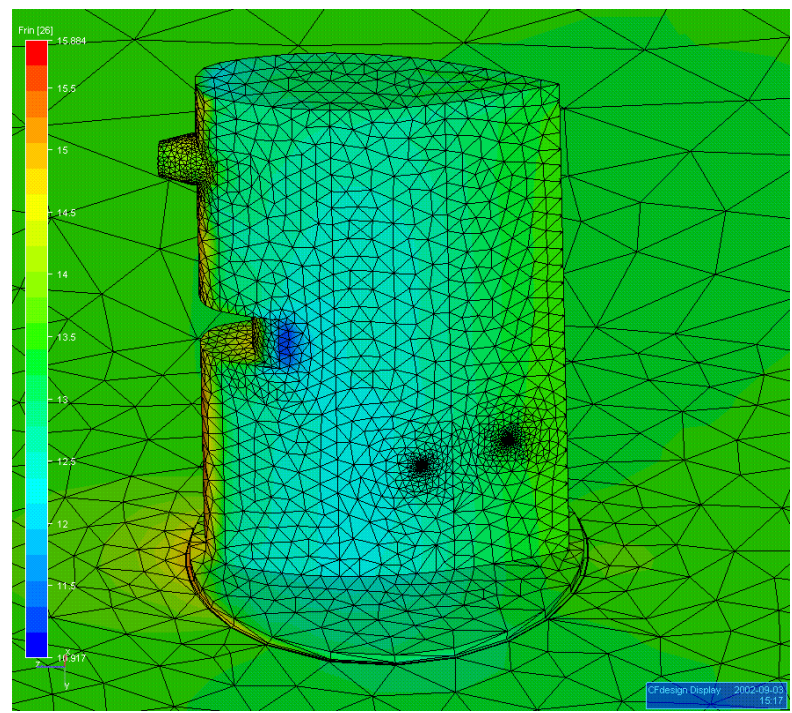

Figure 5. Static Port Mesh Locations

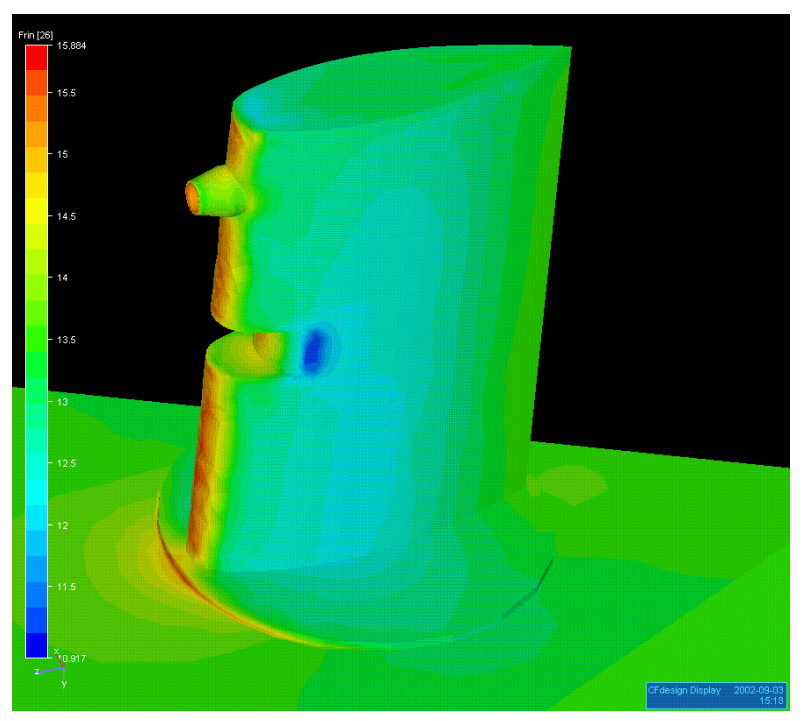

Figure 6. Flow at 250 Knots $10^{\circ}$ Yaw and 5을

All of the TAMDAR models were set up for a flow solution of a turbulent nature, since the Reynolds number at the lowest tested velocity was greater than 1.6E6. The simulations at 125 knots and 250 knots were set up as subsonic compressible flow, while the 534-knot simulation was set up as a fully compressible flow. The solutions were run for 500 iterations, and the trend lines were examined for proper solution convergence.

\subsection{CFD Results}

The results were static pressure, velocity, and turbulence intensity plots. Figure 5 is a captured image of the pressure ports, with a customized scale whose 
intention was to aid in interpreting the results with more precision. Baseline pressure plots were taken perpendicular to the flow inlet and parallel to the sensor's chord length, in between the sensor and control volume wall.

Figure 6 is a plot of the flow velocity on the surface of the probe with a $10^{\circ}$ Yaw angle. Figure 7 is a plot of the pressure field under the same configuration. These two plots indicate that no flow separation from the probe up to $10^{\circ}$ Yaw and $5^{\circ}$ Pitch is present near the static port locations. Since the predicted flow is laminar across the probe, no turbulent flow at the either port location is anticipated under these conditions.

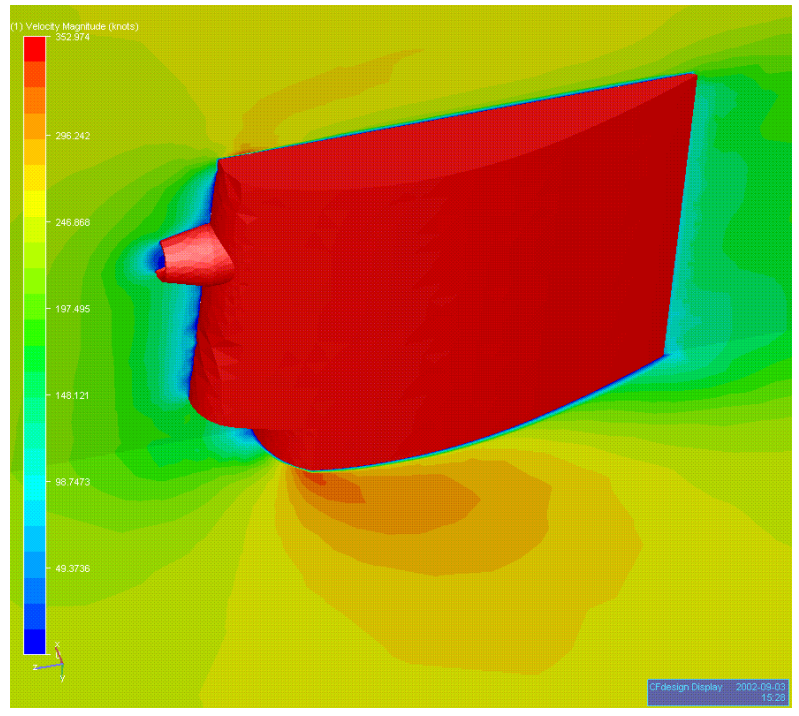

Figure 7. Pressure at 250 Knots $10^{\circ}$ Yaw and $5^{\circ}$ Pitch

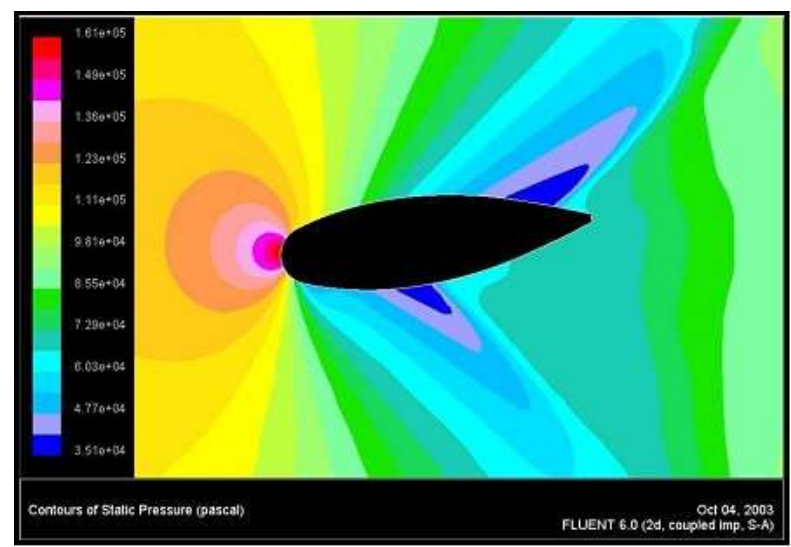

Figure 8. Pressure at Mach 0.8 and Yaw $=8^{\circ}$

\subsection{UND CFD Studies}

A final round of verification tests were performed with the objective to evaluate performance at higher
Mach numbers and verify existing wind tunnel test results. Researchers at UND conducted 2D computational fluid dynamic analyses. The $2 \mathrm{D}$ results show that values for the new static port location should be satisfactory for Mach $=0.8$. Shown in Figure 8 is a plot of a 2D result at Mach 0.8 and $8^{\circ}$ Yaw. These results and others illustrated that the new design performed as desired.

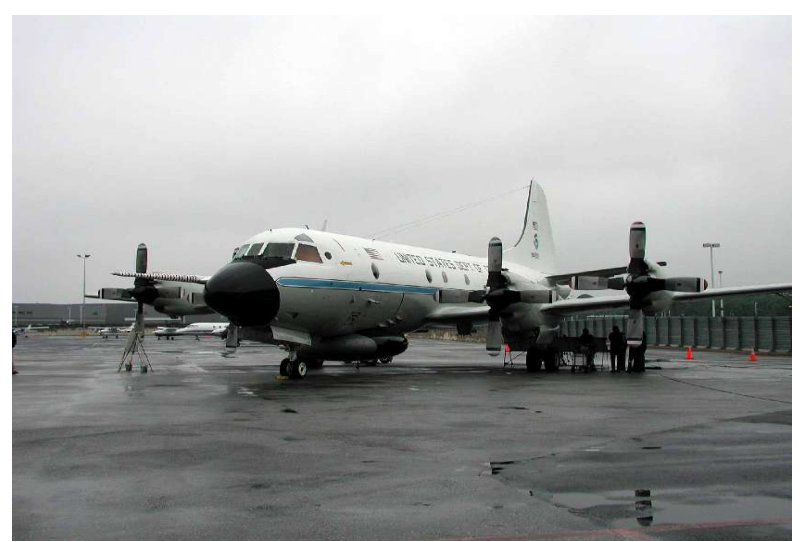

Figure 9. NOAA WP-3D

\section{SENSOR FLIGHT TESTING}

Numerous flight tests were conducted on various aircraft to validate TAMDAR performance against standard instruments. In particular, test flights were conducted on one of NOAA's WP-3D "Hurricane Hunters". This aircraft, shown in figure 9, was selected to measure comparison data because it is instrumented for performing atmospheric research.

\subsection{NOAA P3 Flight Testing Overview}

Two flights were made during the period October 21-23, 2003, from MacDill AFB in Tampa, Florida to a region south of Tampa over the Gulf of Mexico. The first TAMDAR flight was a calibration flight on October 22 2003, providing calibration data for the October 23 flight. The purpose of the second flight on October 23 was to assess the TAMDAR sensor and validate the measured data for accuracy in a variety of atmospheric conditions encountered at different altitudes and airspeeds. Atmospheric data from both NOAA WP-3D's reference instrumentation and a WP-3D dropsonde are compared to the TAMDAR data.

The P3 is a four-engine turboprop plane capable of long duration flights (8-12 hours). In addition, the P3 is equipped to deploy Vaisala Dropsondes, one of which was deployed during the second flight.

Refer to table 3 for the flight test airspeed and altitude matrix. The P3 flew each these nine conditions 
to simulate the anticipated in-service operational flight envelop of the TAMDAR sensor.

\begin{tabular}{|r|r|r|r|}
\hline Altitude (ft) & \multicolumn{3}{|c|}{ Indicated Airspeed (knots) } \\
\hline 1500 & 185 & 195 & 220 \\
\hline 10000 & 180 & 205 & 230 \\
\hline 20000 & 180 & 210 & 235 \\
\hline
\end{tabular}

Table 3. P3 Flight Test Matrix

\subsection{Sensor Configuration}

In order to insure that the probe was outside the boundary layer of the aircraft fuselage, a pedestal was used to position the probe away from the aircraft skin, as shown in Figure 11. Normally the flange on the probe base is flush with the aircraft skin. With the pedestal, the flange is about four inches from the skin. The probe itself was separated from the SPU with extension cables connecting the probe electronics to the SPU. Longer tubing connected the static and pitot ports to barbs on the SPU.

For winds computations, aircraft heading was supplied to the SPU by a P3 on-board computer. The TAMDAR firmware was modified to accept the data format supplied.

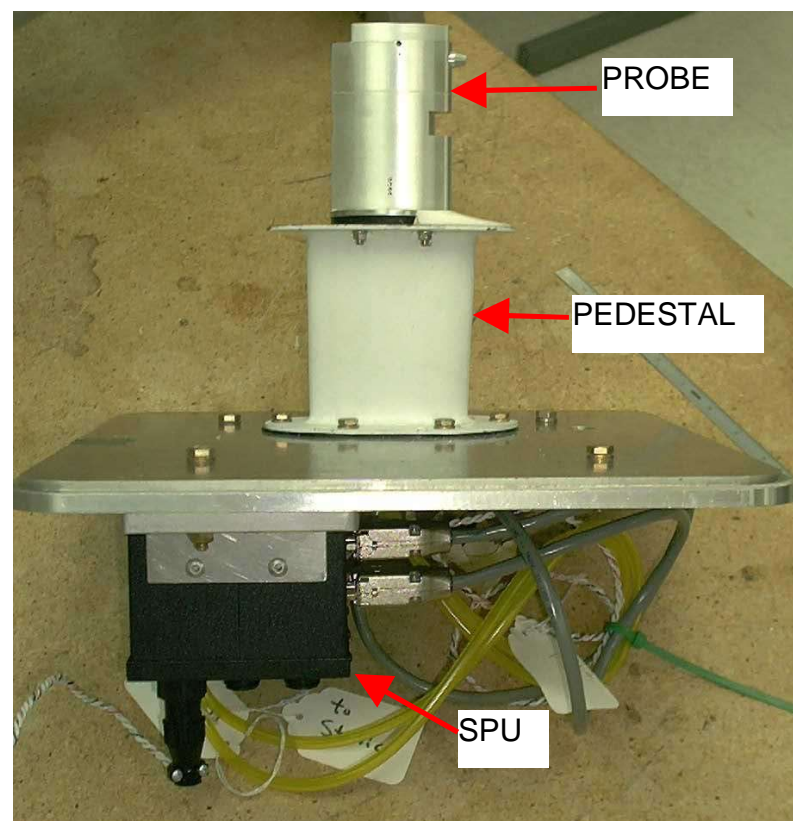

Figure 10. TAMDAR Installation for P3

\subsection{P3 Installation}

As shown in figure 11, the probe on the pedestal was mounted on the side of the aircraft at approximately 30 degrees relative to horizontal. Normally the probe is oriented downward to facilitate drainage but in this case it's oriented at an upward angle. An important consideration in selecting the final location was the minimization of turbulent airflow at the probe location that could adversely affect turbulence, airspeed, and pressure altitude measurements. The airflow at the probe location was characterized by installing a pitot/static probe in place of the TAMDAR probe. Data from the pitot/static probe was recorded while the probe was adjusted to different distances from the aircraft skin. Examination of this data verified the suitability of this location.Data for the P3 reference instruments was logged on a P3 computer while a separate laptop computer logged the TAMDAR data. Both flights consisted of a leg from MacDill AFB to an area above the Gulf of Mexico (with several racetrack patterns at various altitudes), and a return leg to MacDill AFB.

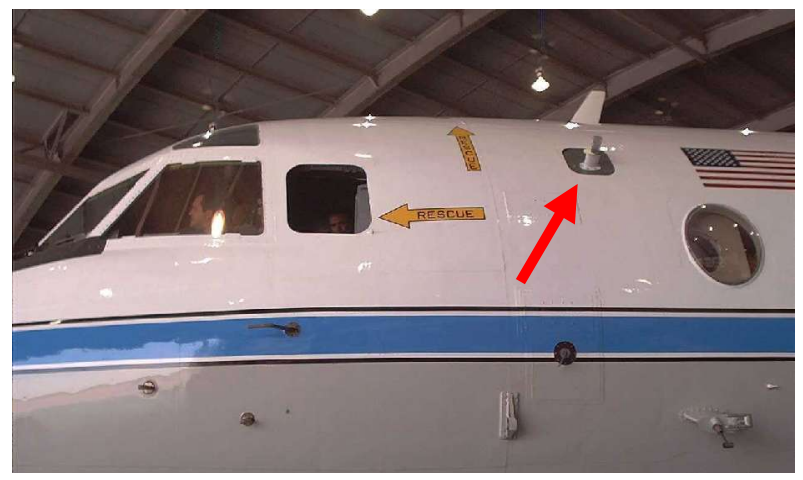

Figure 11. P3 With TAMDAR Installed

\subsection{Flight Results}

The data analyzed was taken during the time the aircraft speed was above 80 knots; only obviously errant data points were eliminated for the RMS analysis. The flight data was analyzed by comparing temporal TAMDAR data with the P3 reference data. Analysis was also done by plotting altitude profiles of TAMDAR, P3 and dropsonde data. The analysis of the various measurements includes graphs showing the P3 reference instrumentation and TAMDAR data over time; the deviation (or error) between the TAMDAR reading and the P3 reference over time; and altitude profiles of applicable parameters of dropsonde reference, P3 reference and TAMDAR data. A series of plots follow that present these results.

The RMS error is the square root of the sum of the squares of the bias and the standard deviation for the error data. Additionally a statistical error analysis is presented for the whole flight, and the results are listed in Table 3. 


\subsection{Dropsonde}

An NCAR GPS dropsonde, also know as Airborne Vertical Atmospheric Profiling System (AVAPS) dropsonde was launched at approximately 53300 SFM. Temperature and relative humidity data is shown in figure 12 while wind magnitude and direction are shown in figure 13. A comparison to P3 and TAMDAR data is made with only the first or initial values from the dropsonde. The initial values for temperature, relative humidity, and wind compare favorably with corresponding TAMDAR measurements.

\subsection{Pressure Altitude}

Refer to Figure 14 for the pressure altitude plots. The plot encompasses the entire flight profile. At the low altitude (1500 feet), the error is correlated to airspeed implying an angle-of-attack dependence. A slight dependence is seen at 10,000 feet at each of the three airspeeds. This dependence is not seen at the highest altitude or airspeeds.

\subsection{Airspeed}

Refer to figure 15 and figure 16 for indicated airspeed and true airspeed plots, respectively. Also shown on each plot are the errors or differences between P3 and TAMDAR. The plot encompasses the entire flight profile. As in the case of pressure altitude, there is a high degree of correlation between error and airspeed at the lowest altitude. The likely cause is static port output dependence on angle of attack. Again, this trend does not appear at the higher altitudes.

\subsection{Temperature}

Ambient temperature measurements and the error difference are shown in figure 17. Close tracking between TAMDAR and the P3 reference temperatures are seen in the plot. The plot encompasses the entire flight profile. The AVAPS dropsonde time span is shown on this plot.

\subsection{Temperature Altitude Profile}

The temperature profiles for TAMDAR, P3 and Vaisala Dropsonde are shown in figure 18. The plot encompasses the entire flight profile. This figure should be used for a determination of how well TAMDAR measures temperature during changes in altitude. The profiles for all three track well except for temperatures from about 12 to $14 \mathrm{C}$ where the dropsonde deviates from TAMDAR and the P3. This is most likely because of the temporal and spatial difference between the sets of data. Several erroneous data points can be seen in the Vaisala data; the reason for these is unknown.

\subsection{Winds Aloft}

The time plots for the wind direction are shown in figure 19 and the vector magnitude error is shown in figure 20 . The plot encompasses the entire flight profile. The vector magnitude error is defined as the magnitude of the difference between the TAMDAR reported wind velocity vector and the P3 reported wind velocity vector. Heading data for the winds aloft calculation done in the TAMDAR sensor was supplied to TAMDAR via a serial report from the P3's on-board navigation system. Occasionally the heading data supplied was clearly in error, which resulted in errors in TAMDAR calculation of wind heading and speed. These errors usually resulted in a heading of 999 degrees (an error condition) being used in the TAMDAR calculation. The erroneous points were eliminated in the calculation of the RMS error and the standard deviation of vector magnitude error.

The racetrack patterns on the flight were generally with the wind or into the wind. Examination of figure 19 indicates a periodic wind direction error that is synchronous with the racetrack patterns. It was suspected that an offset in the heading supplied to TAMDAR from the P3 system could account for the heading errors. The winds aloft data was postprocessed and an offset of -0.985 degrees was added to the heading. The winds aloft were then recalculated. As can be seen in figure 20, the addition of this offset brought the TAMDAR wind direction significantly closer to the P3 reference. The actual offset number was determined by minimizing the RMS vector magnitude error of the winds.

It should be noted that the $\mathrm{P} 3$ reference data also shows periodicity with the racetrack patterns indicating questionable accuracy of the reference.

\subsection{Winds Aloft Profile}

Figure 21 and figure 22 show close agreement on the winds aloft profiles for TAMDAR, P3 and the dropsonde. This figure should be used for a determination of how well TAMDAR computes winds aloft during changes in altitude. For both plots, comparison of the different data sets should only be done when the P3 was changing altitudes between the values given in table 3 .

\subsection{Humidity}

The humidity versus time plot is shown in figure 23 . TAMDAR and P3 reference data are shown. The basic measurement of the P3 reference equipment is dew point. The dew point was converted to relative humidity based upon the saturation pressure of water. The P3 software performed this conversion. Because the response of the P3 sensor was very fast and had some 
overshoot, a filtered version of the P3 data is used. The filter used was a 10 second moving average filter, which approximates the response of the IIR filter used by TAMDAR on all of its sensors.

The laser hygrometer was used for comparison because the chilled mirror data had gaps due to the removal of invalid data. Only one of the TAMDAR capacitive humidity sensors is plotted because both TAMDAR RH sensors reported nearly identical results. This indicates excellent repeatability for the capacitive sensors used in TAMDAR. The largest errors occurred during very cold temperatures: less than $-28 \mathrm{C}$. The air at these temperatures contains very little moisture. Very low temperature performance can be improved with better calibration data.

TAMDAR values for relative humidity are provided either with respect to liquid water or with ice depending on the ambient temperature.

\subsection{Humidity Altitude Profile}

Since both TAMDAR humidity sensors tracked so closely, only output from one sensor is shown in figure 24. P3 and dropsonde data are also shown in this figure. This figure should be used to determination how well TAMDAR measures relative humidity during changes in altitude. Note the improvement in accuracy as the altitude decreases (the P3 and TAMDAR plots start to converge as altitude decreases). This is due to an increase in the amount of available moisture.

\subsection{Icing and Turbulence}

No icing events occurred during the flights and none were reported by TAMDAR. Also, no reference data from the P3 instrumentation was available for comparison of TAMDAR turbulence results. The flight crew noted no particularly turbulent events during the flight. Icing results are presented in Murray, et al., 2004.

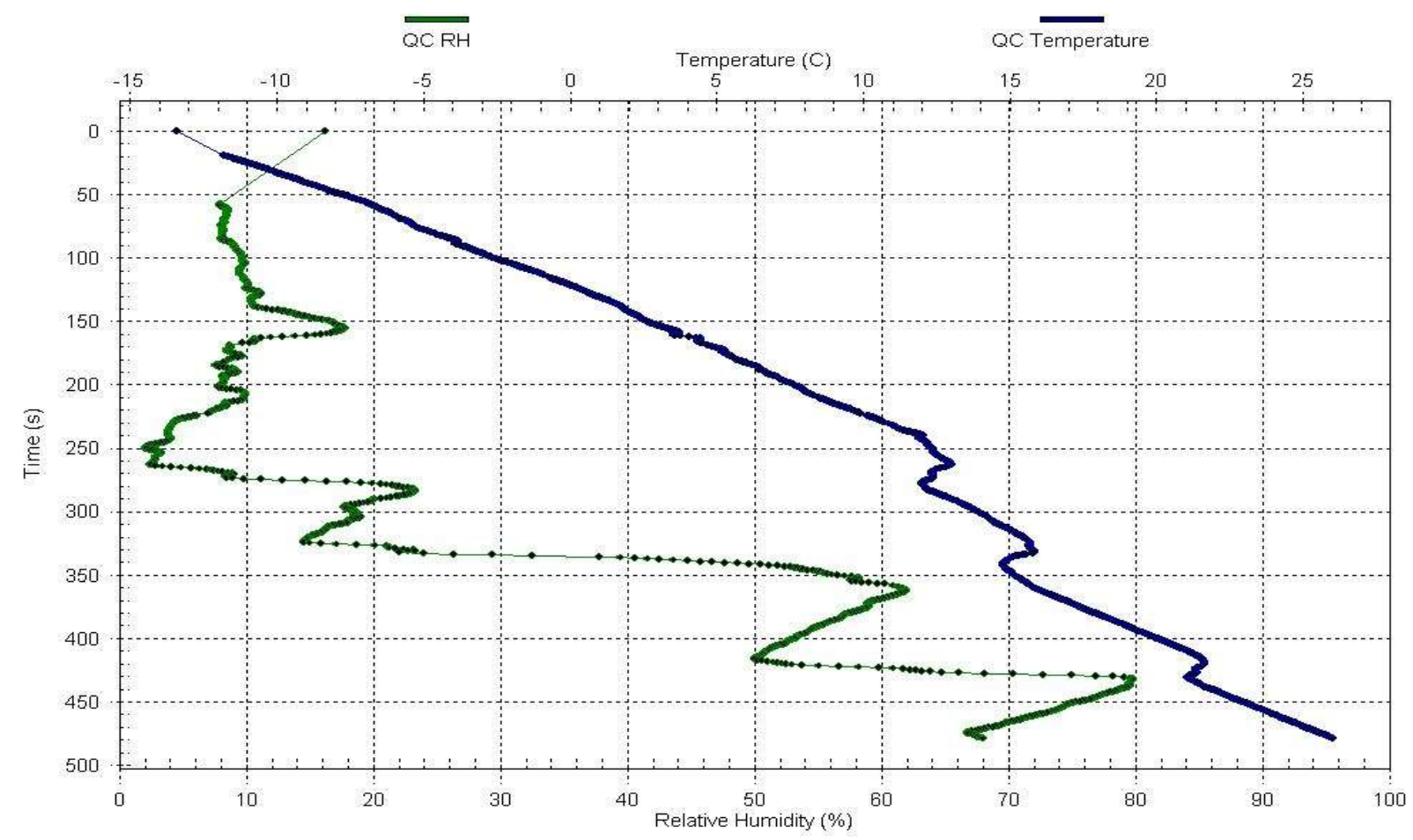

Figure 12. AVAPS Time versus Temperature and Relative Humidity 


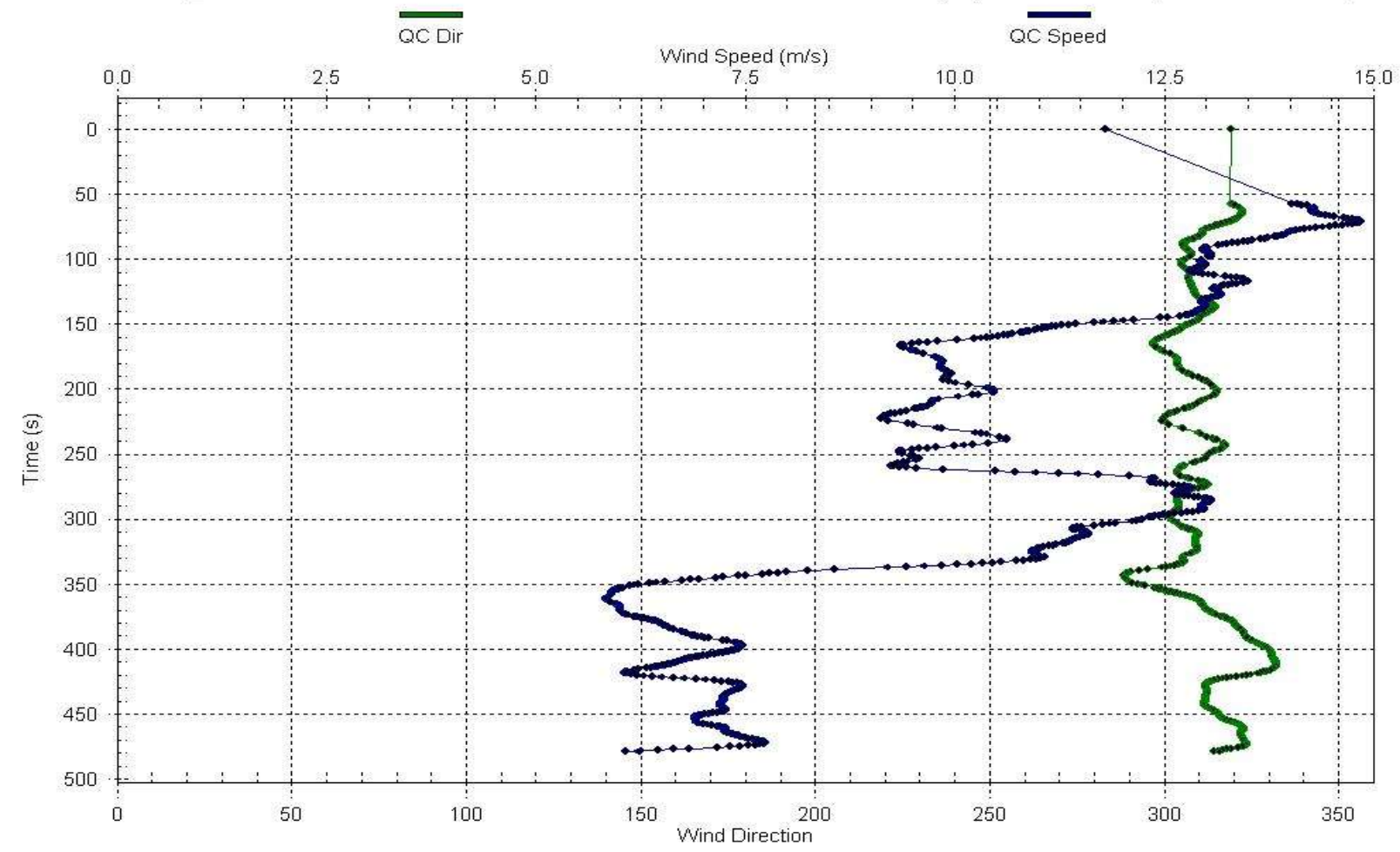

Figure 13. AVAPS Time versus Wind Speed and Wind Direction

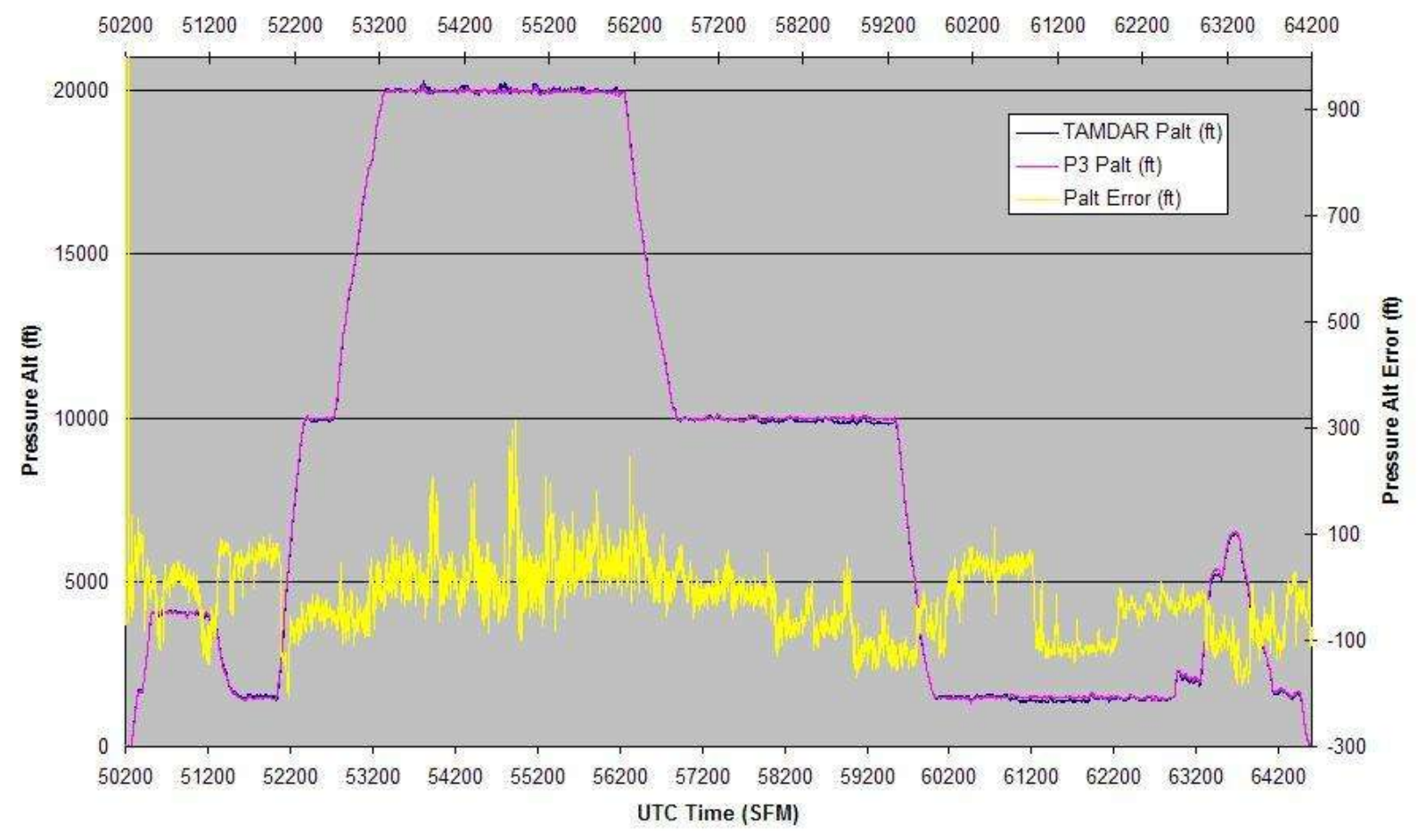

Figure 14. Pressure Altitude and Error 


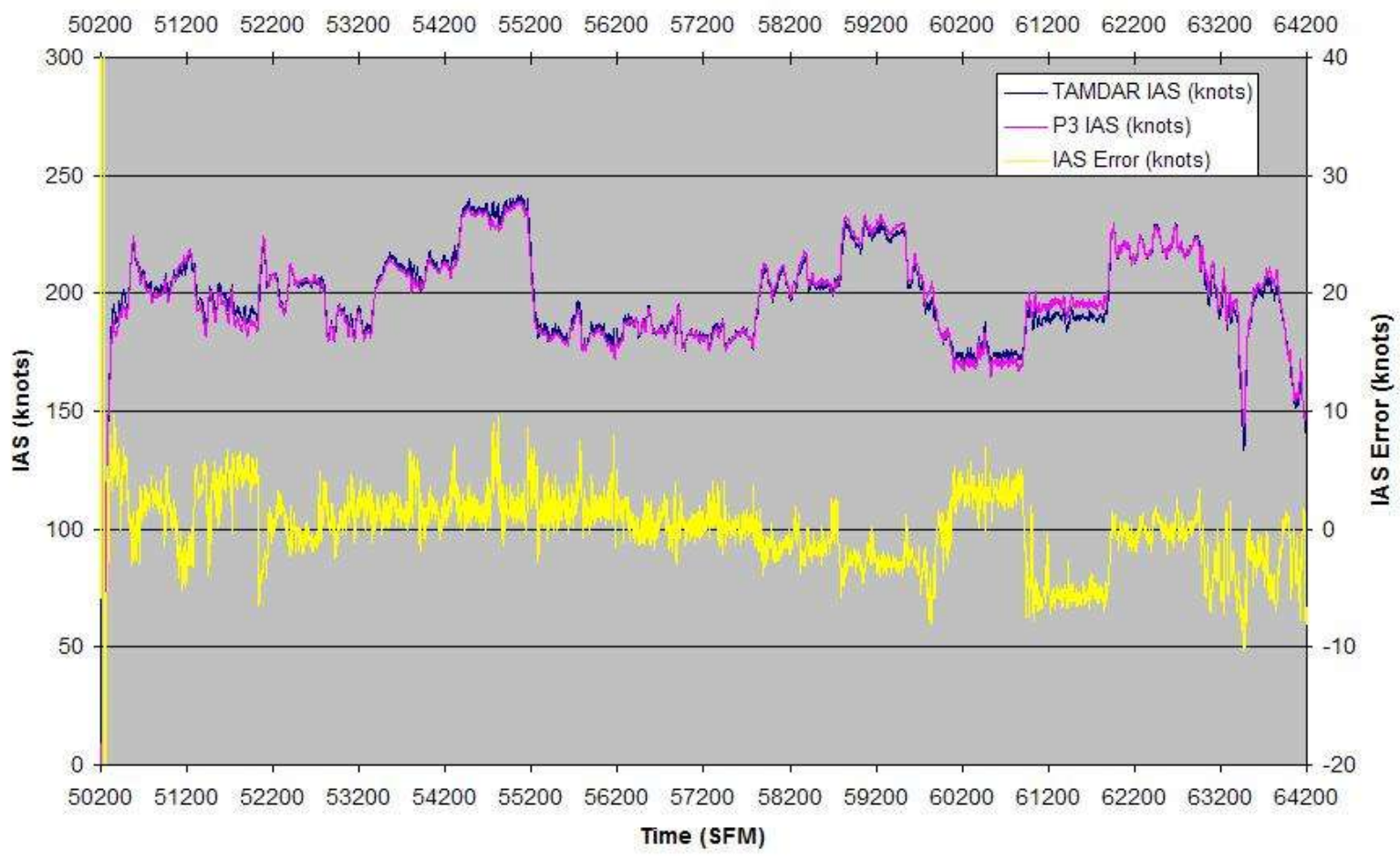

Figure 15. Indicated Airspeed and Error

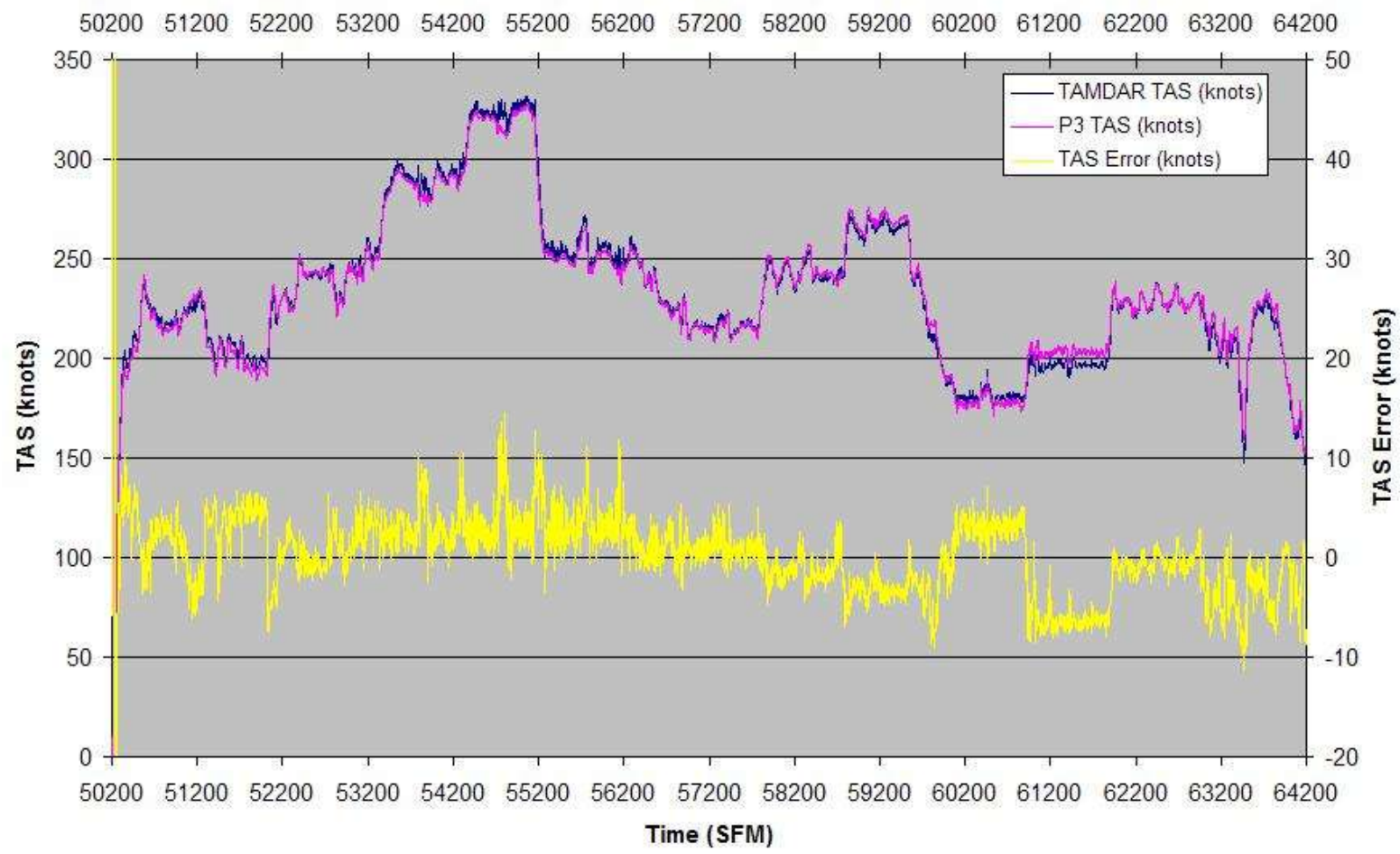

Figure 16. True Airspeed 


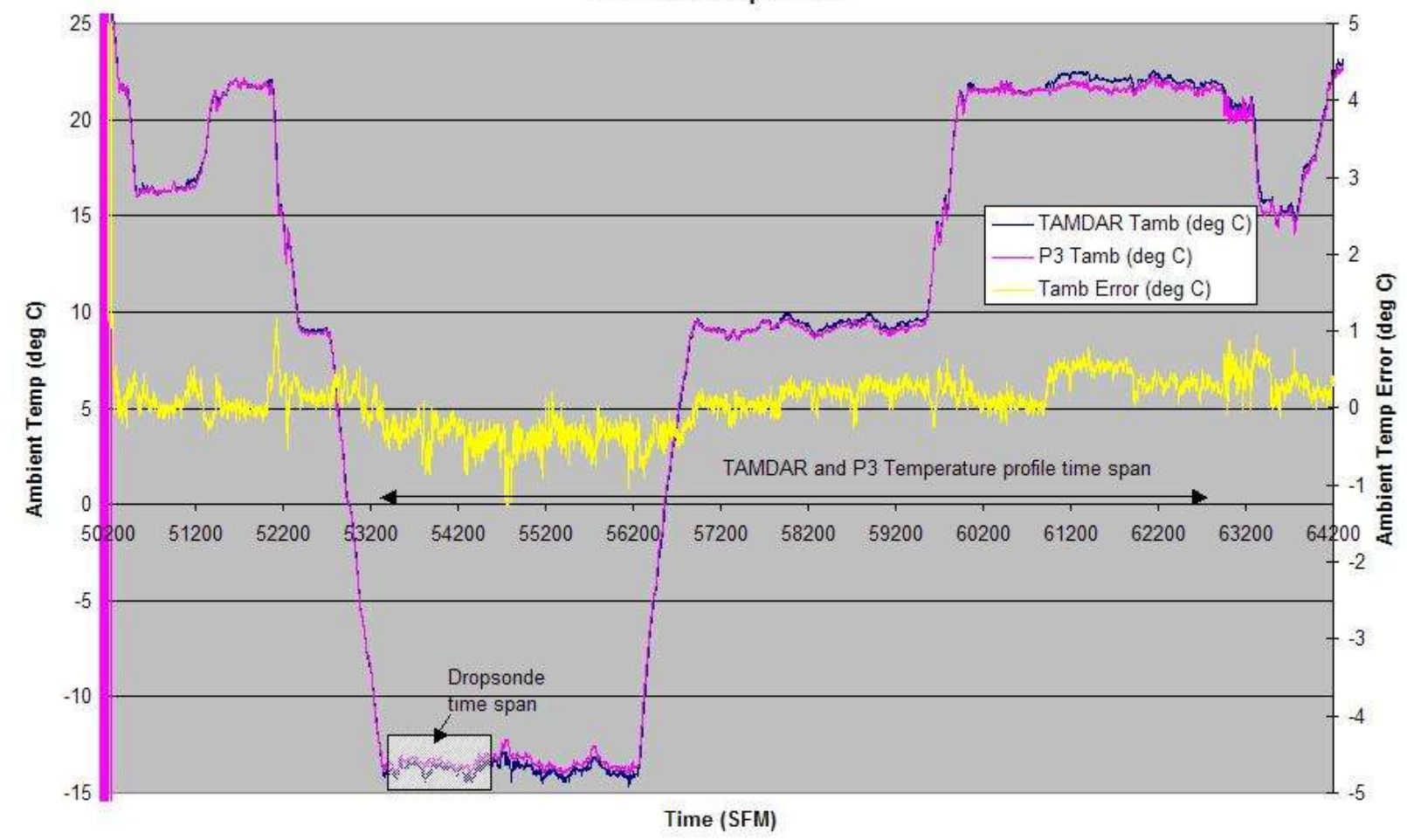

Figure 17. Temperature and Error

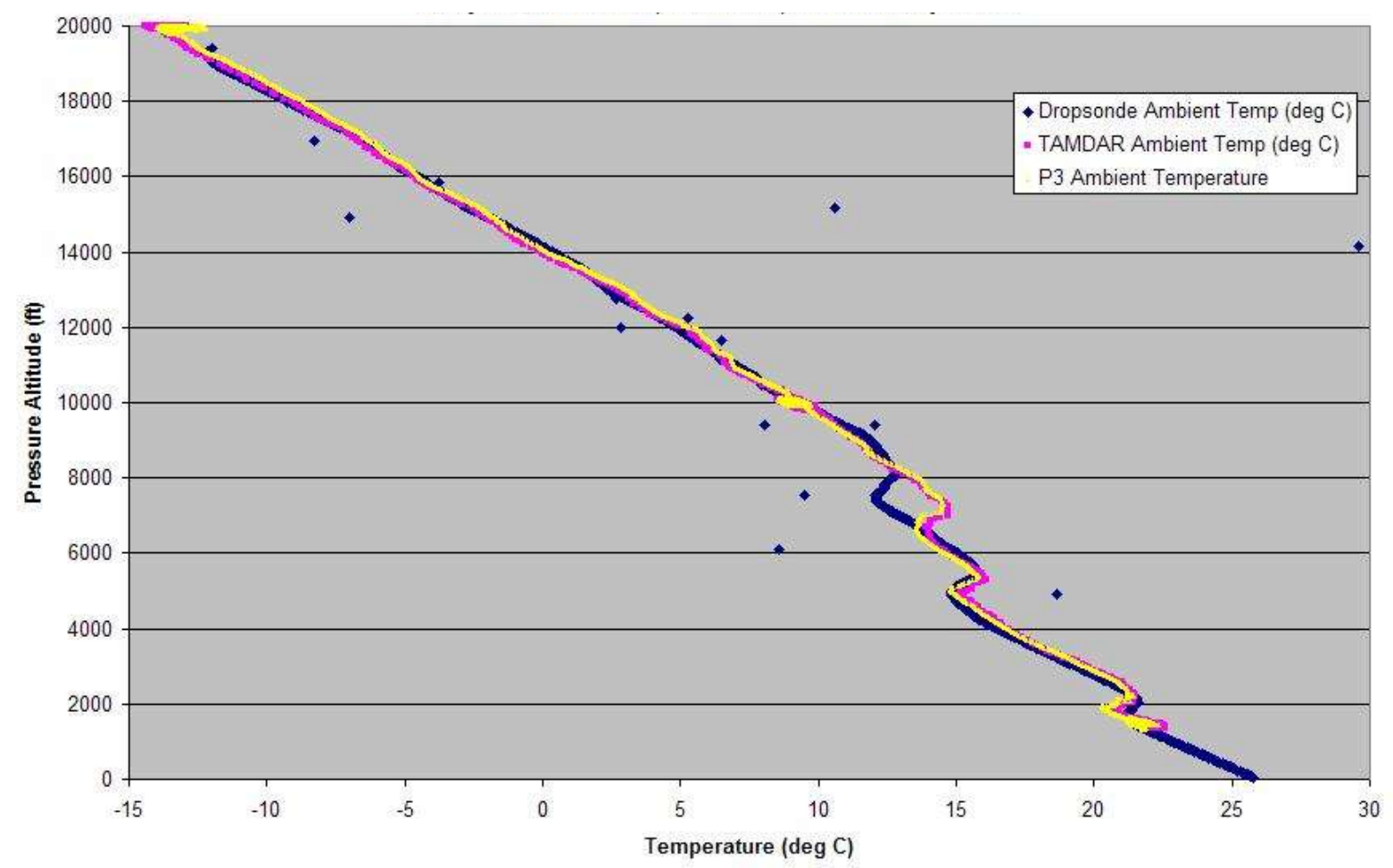

Figure 18. Temperature Altitude Profile (TAMDAR and P3 data set: 54127 to 62828 SFM) 


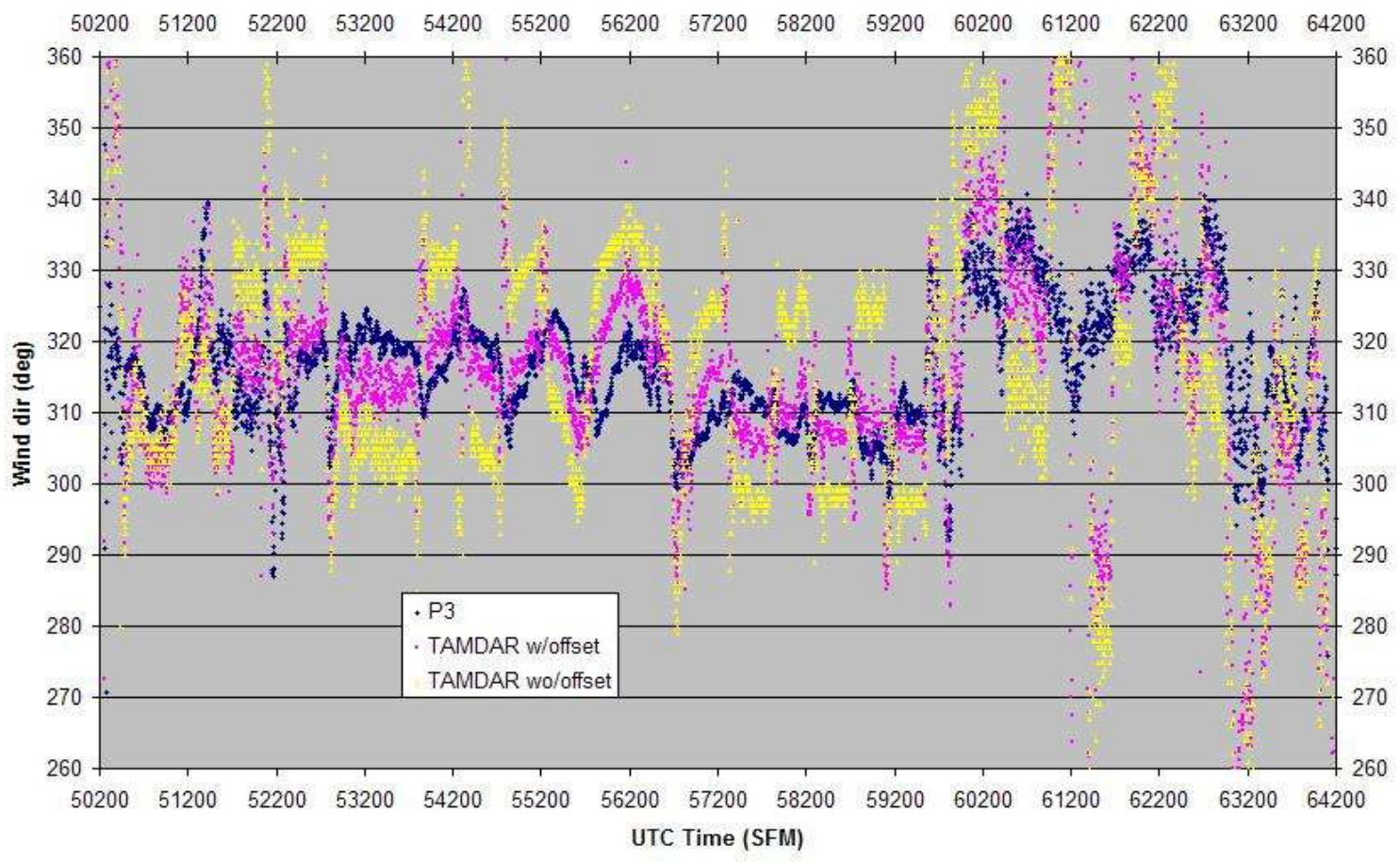

Figure 19. Winds Direction With and Without Post-Processed Heading Offset

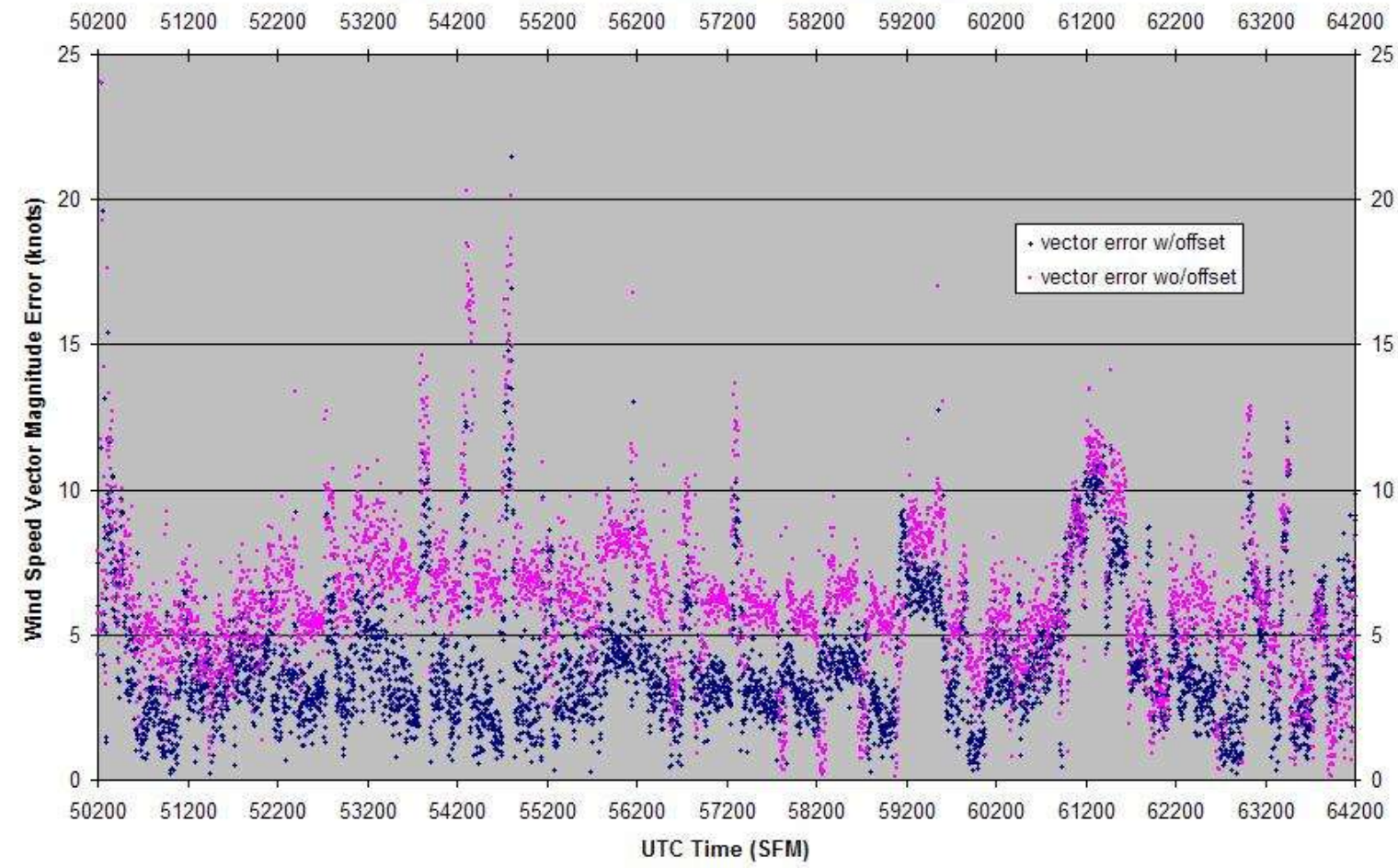

Figure 20. Winds Aloft Vector Magnitude Error (TAMDAR - P3) With and Without Post-Processed Heading Offset 


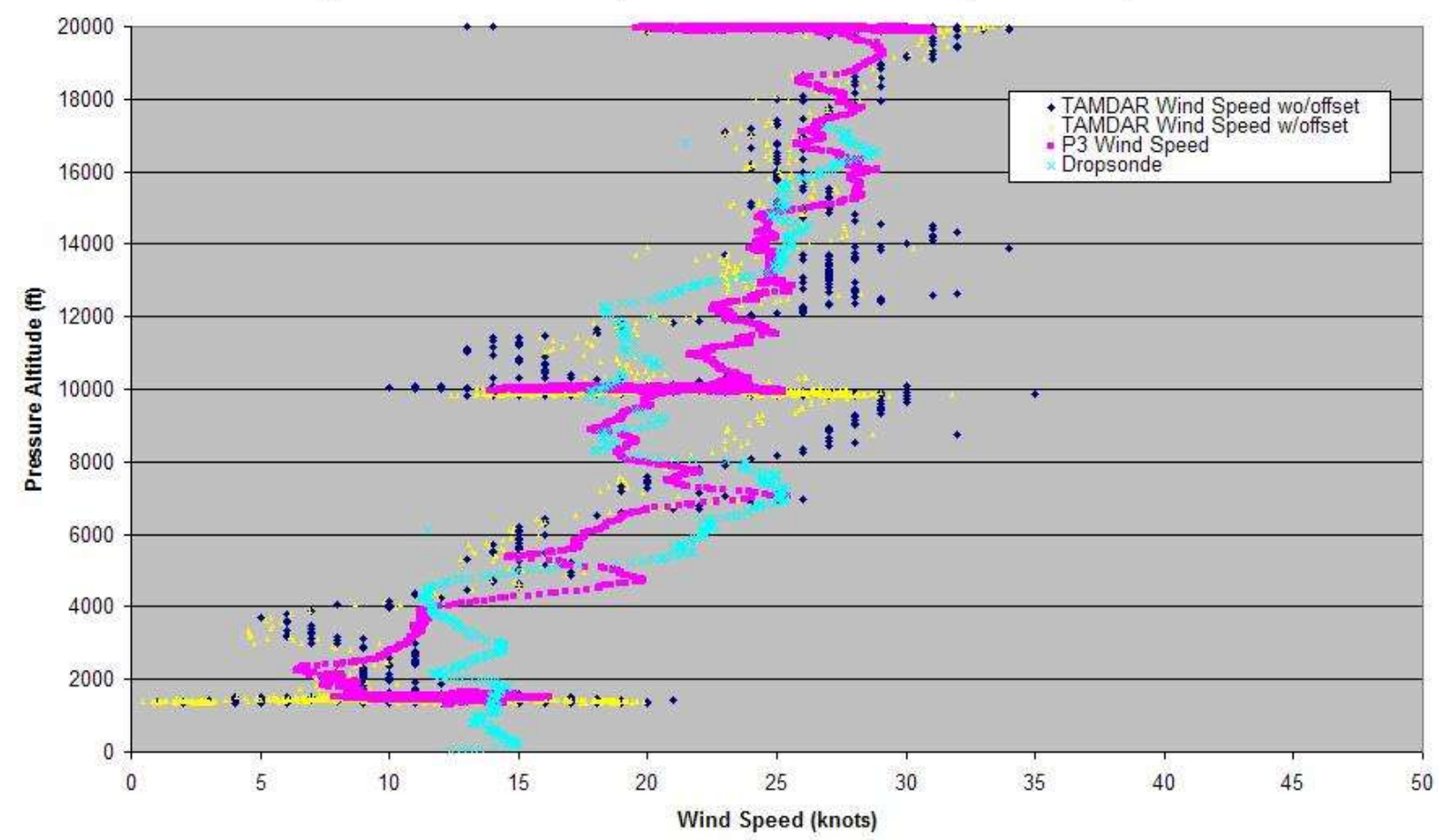

Figure 21. Winds aloft speed profile. TAMDAR (with and without post-processed heading offset), P3, and Dropsonde.

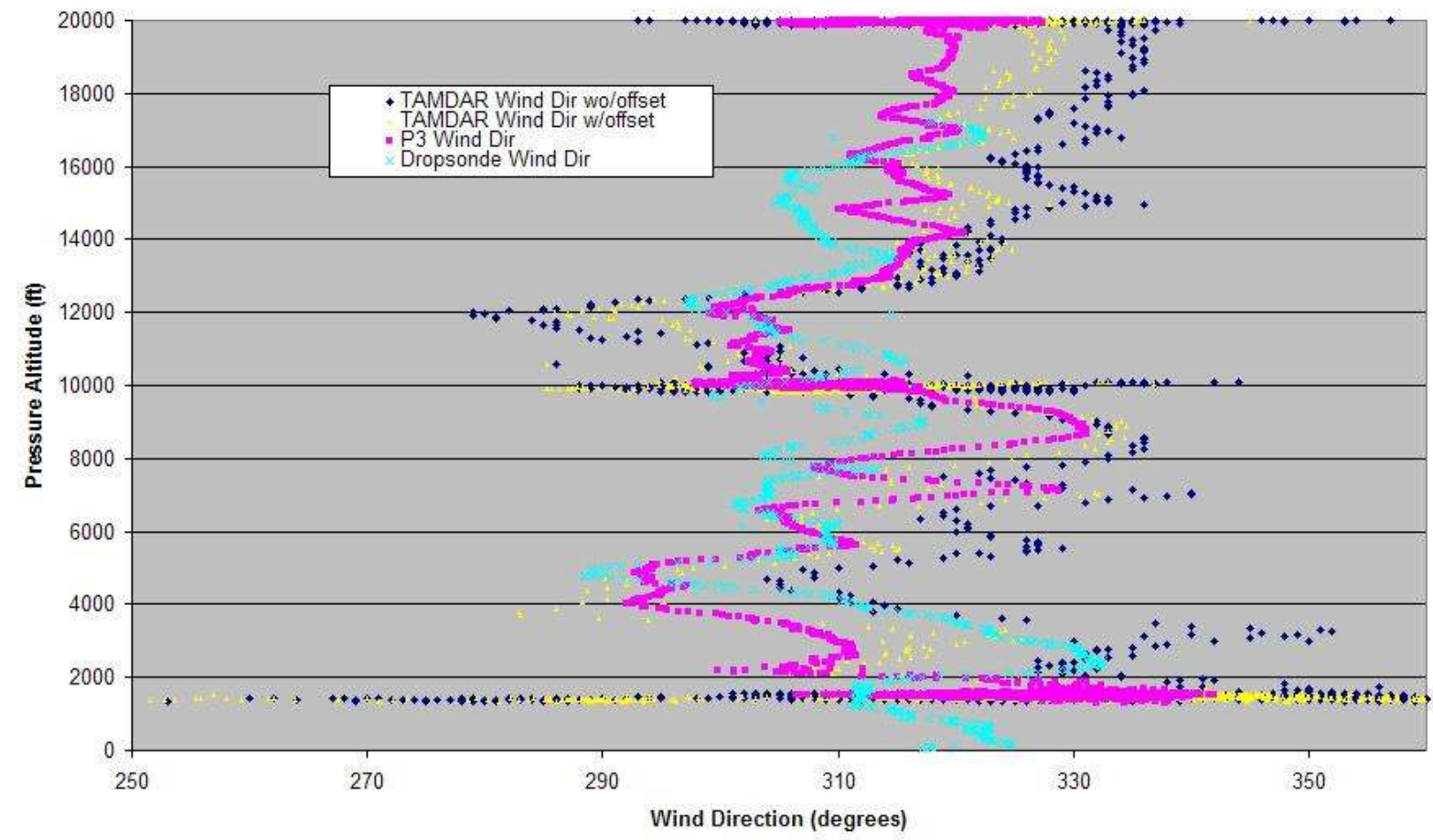

Figure 22. Winds Aloft Direction Profile. TAMDAR (With And Without Post-Processed Heading Offset), P3, and Dropsonde. 


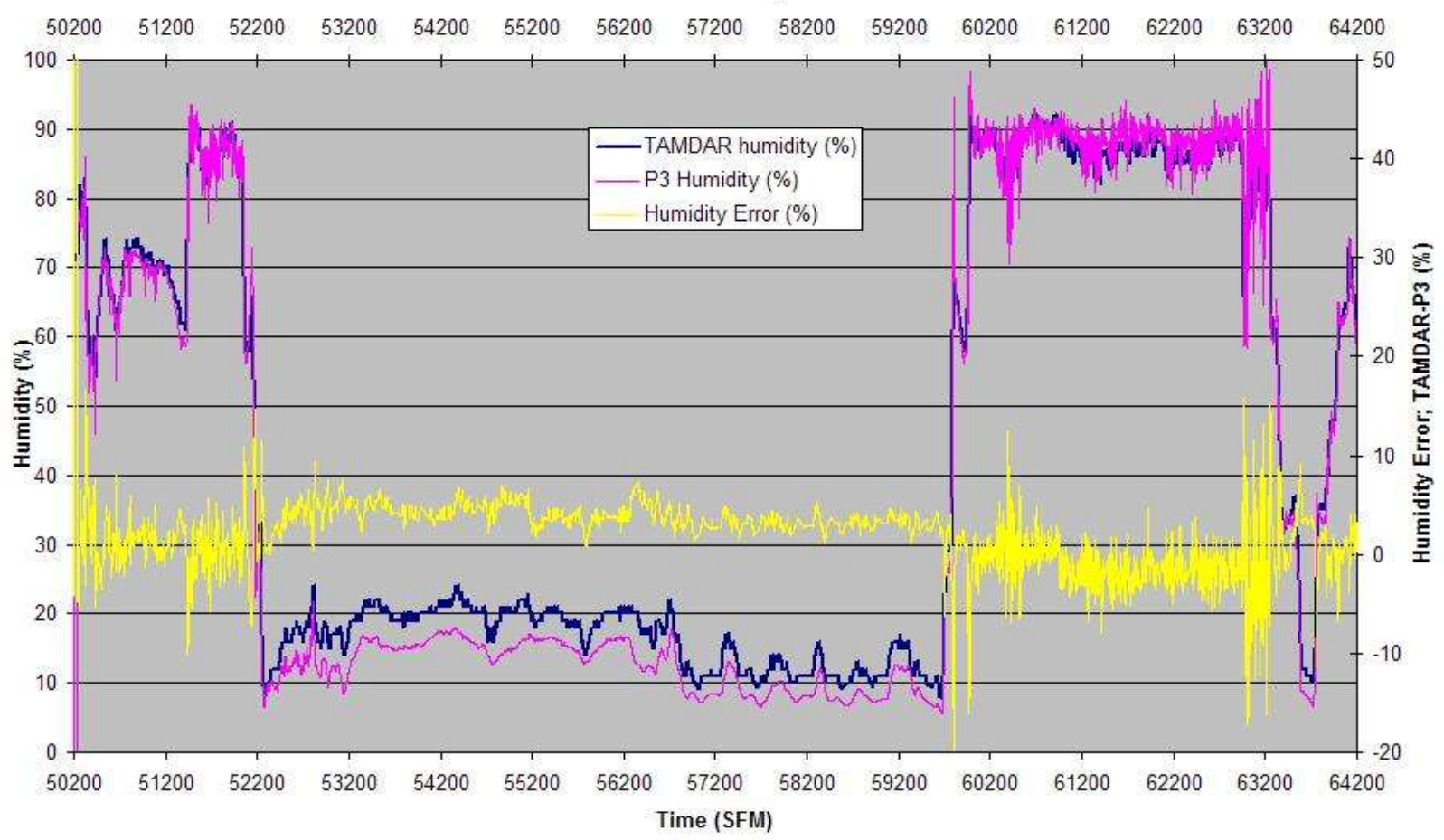

Figure 23. Humidity And Error

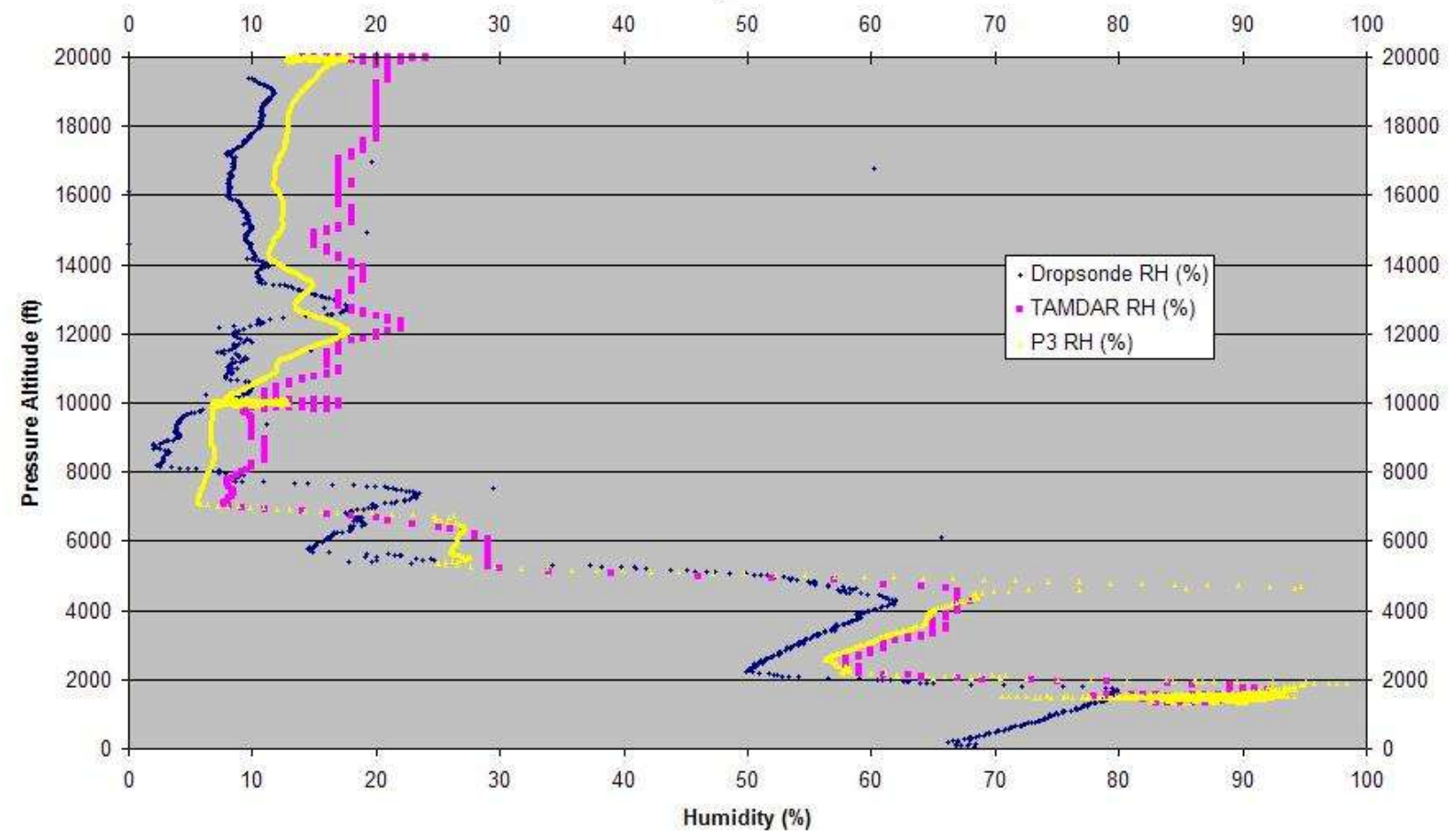

Figure 24. Humidity Altitude Profile 


\begin{tabular}{|c|c|c|c|c|c|}
\hline \multicolumn{2}{|l|}{ Parameter } & $\begin{array}{l}\text { RMS } \\
\text { error }\end{array}$ & Bias & $\begin{array}{l}\text { Standard } \\
\text { deviation }\end{array}$ & $\begin{array}{l}\text { TAMDAR target } \\
\text { requirements }\end{array}$ \\
\hline \multicolumn{2}{|l|}{ Pressure altitude (feet) } & 71.3 & -21 & 67.9 & $+/-150$ feet \\
\hline \multicolumn{2}{|l|}{ TAS (knots) } & 3.7 & 0.1 & 3.7 & $+/-4$ knots \\
\hline \multicolumn{2}{|l|}{ IAS (knots) } & 3.1 & -0.056 & 3.1 & $+/-3$ knots \\
\hline \multicolumn{2}{|l|}{ Temperature $(\mathrm{C})$} & 0.33 & 0.073 & 0.32 & $+/-1 \operatorname{deg} C$ \\
\hline Relative humidity (\%) & All data & 3.7 & 2 & 3.1 & Not specified \\
\hline \multirow{2}{*}{$\begin{array}{l}\text { Winds aloft vector } \\
\text { magnitude }\end{array}$} & No Heading offset & 2.5 & NA & 2.5 & $+/-6$ knots \\
\hline & $\begin{array}{l}0.985 \text { deg heading } \\
\text { offset (post- } \\
\text { processed) }\end{array}$ & 2.3 & NA & 2.3 & \\
\hline
\end{tabular}

Table 4. Error Statistics For P3 Flight Tests.

\subsection{Performance Summary}

Table 4 summarizes the statistics of the probe performance relative to the P3 reference instrumentation. All of the performance goals have been met by the TAMDAR sensor design.

\section{DISCUSSION AND CONCLUSIONS}

The analysis summary in Table 4 consists of essentially the whole flight, which included the range of conditions envisioned for TAMDAR.

Although no turbulence information was included in the P3 reference data, the TAMDAR turbulence "noise floor" is higher than would be expected. Probe misalignment or slightly turbulent airflow in the vicinity of the probe may be the cause.

There was a suspected angle-of-attack dependence effect on the static port, which caused some inaccuracy in airspeed and pressure altitude at low altitudes (about 1500 feet). The orientation of the probe may not be the best for the varying angles-ofattack typically seen by the P3. Past experience has shown that changing the angle of the probe blade to the airflow may correct these problems. There was no mechanism to do that for these flight tests.

Periodic wind direction errors synchronous with the racetrack patterns were noted. Assuming that an offset in the heading supplied to TAMDAR from the P3 system accounts for the heading errors, the winds aloft data were post-processed, and an offset of -0.985 degrees was added to the heading. The addition of this offset brought the TAMDAR wind direction significantly closer to the $\mathrm{P} 3$ reference.

It should be mentioned that wind direction and wind speed errors alone are not a very consistent way to characterize performance because they depend heavily on the conditions. For example, racetrack patterns flown into and away from the wind, as was the case with the P3, will result in greater direction errors than if they were done perpendicular to the wind. Low wind speeds in the former case will result in greater direction errors than high wind speeds. It is for this reason that the magnitude of the wind error vector is the preferred measurement of accuracy. This is the method used in the AMDAR Reference Manual (WMO 2003). It should also be noted that the P3 data exhibited the same periodicity effect with the racetrack pattern implying that it also may have errors.

Experience has shown that if care is taken on probe location selection, and if the results are analyzed to produce accurate calibration constants that are then uploaded to the TAMDAR sensor, excellent results are obtained in subsequent flights. This process need only be done once for a given aircraft and configuration.

These flight tests demonstrated TAMDAR performance as an accurate meteorological instrument for the measurement of temperature, pressure altitude, relative humidity, and winds aloft. Turbulence and icing performance could not be verified on these flights because of the lack of reference data and icing conditions.

\section{GREAT LAKES FLIGHT EXPERIMENT}

The Great Lakes Flight Experiment (GLFE) is planned as a field campaign as a final flight experiment for the TAMDAR sensor development (Moninger et al., 2004). The hypothesis is that the number and size of significant weather forecast errors over the Great Lakes Region can be reduced by incorporating extra observations from the TAMDAR sensors installed on Mesaba Airlines Saab 340 aircraft. The installation block diagram is shown in figure 25 .

Representatives of Mesaba Airlines have agreed to participate in this experiment. Mesaba has revenue flights with 64 Saab 340 twin-turboprop aircraft in the Great Lakes region. The duration is six months after all of the aircraft are equipped by Fall 2004.

The primary aim of the GLFE is to test the real-time impact of TAMDAR observations on Rapid Update Cycle forecast model skill. Additional scientific 
objectives of the GLFE will include improving weather products from local National Weather Service (NWS) offices and determining the impact of quality control algorithms of collected TAMDAR data with other observations.

During the GLFE, local weather forecasters at NWS offices will have access to real-time data on their AWIPS workstations from the NOAA FSL MADIS database via LDAD. The data will also be available on the FSL MDCRS and AirDat websites.
After the GLFE, data will be analyzed to gauge the impact of the TAMDAR data on aviation safety; model forecast skill, and local weather forecast accuracy. While NASA's Aviation Safety Program has the goal of reducing aviation accidents within all aircraft classes, the measurable impact of TAMDAR will likely require analysis of long term statistics on accident rates. Regarding the two types of weather forecasts, the benefits of TAMDAR will be more apparent.

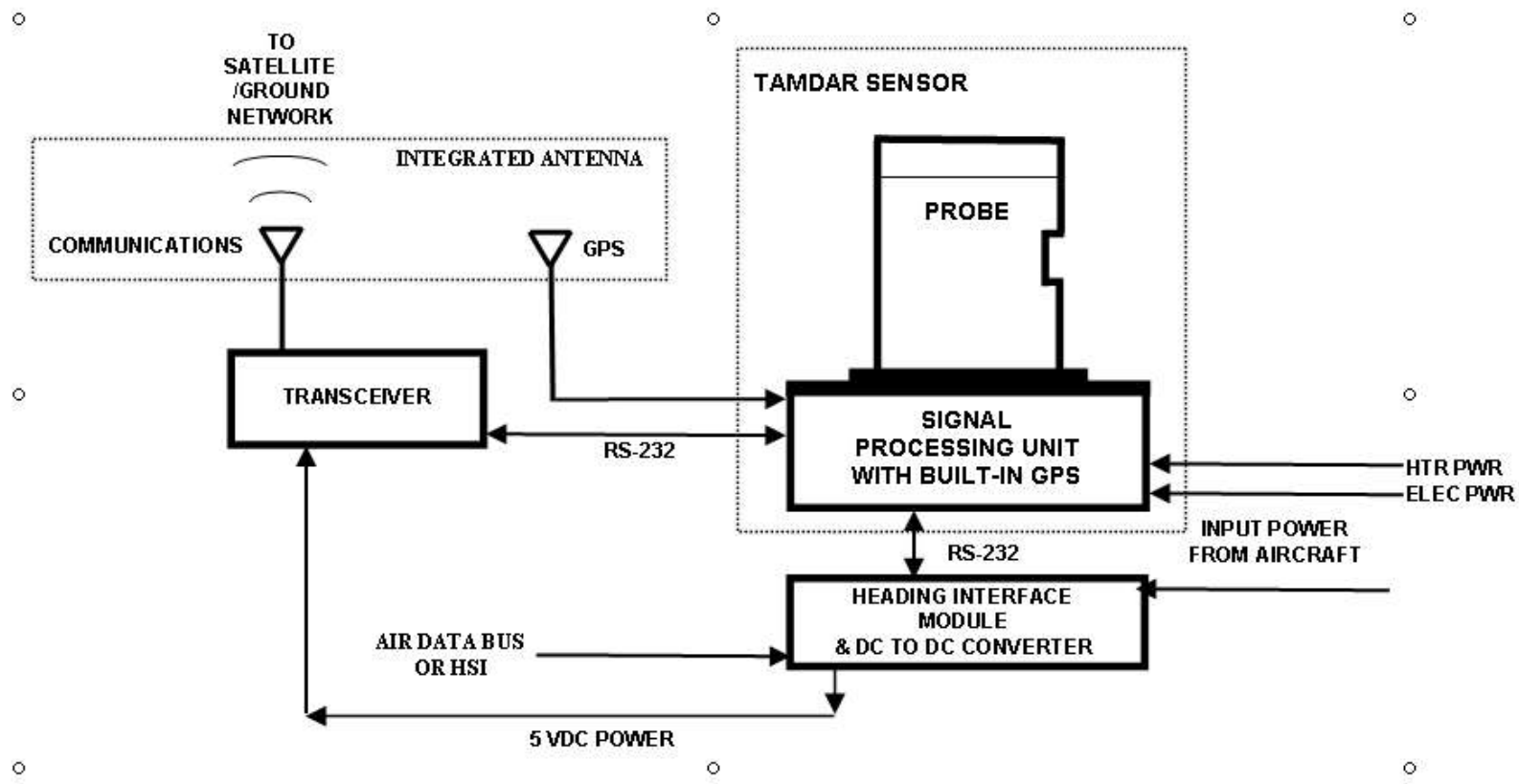

Figure 25. TAMDAR System Block Diagram

\section{ACKNOWLEDGEMENTS}

This effort was partially funded by FAA Interagency Agreement DTFA-01-01-X-02030.

\section{BIBLIOGRAPHY}

American Meteorological Society Council, "Support for Automated Observations from U.S. Commercial Aircraft," Bull. Amer. Met. Soc., 84, 515-517, Adopted by AMS Council on 9 February 2003.

Taumi S. Daniels, "Tropospheric Airborne Meteorological Data and Reporting (TAMDAR) Sensor Development." SAE General Aviation Technology Conference and Exposition, 2002-011523, April 2002.

Paul B. McCready, Jr., "Standardization of Gustiness Values from Aircraft," Journal of Applied Meteorology, August 1964, Vol. 3, pp. 439-449.
William Moninger, T. Daniels, R. Mamrosh, M. Barth, S. G. Benjamin, R. Collander, L. Ewy, B. Jamison, R. Lipschutz, P. Miller, B. Schwartz, T. Smith, and E. Szoke, 2004: TAMDAR, the Rapid Update Cycle, and the Great Lakes Fleet Experiment. 11th Conf. on Aviation, Range, and Aerospace Meteorology, Hyannis, MA, Amer. Meteor. Soc.

John Murray, A. Grainger, P. Minnis, L. Nguyen, C. Wolff, P. Schaffner, 2004: The 2003 Alliance Icing Research Study (AIRS II) Evaluation of Tropospheric Airborne Meteorological Data Reporting (TAMDAR) lcing Sensor. 11th Conf. on Aviation, Range, and Aerospace Meteorology, Hyannis, MA, Amer. Meteor. Soc.

WMO 2003: "Aircraft Meteorological Data Relay (AMDAR) Reference Manual," WMO Publication No. 958. World Meteorological Organization, Geneva, Switzerland 


\section{APPENDIX TAMDAR SPECIFICATIONS}

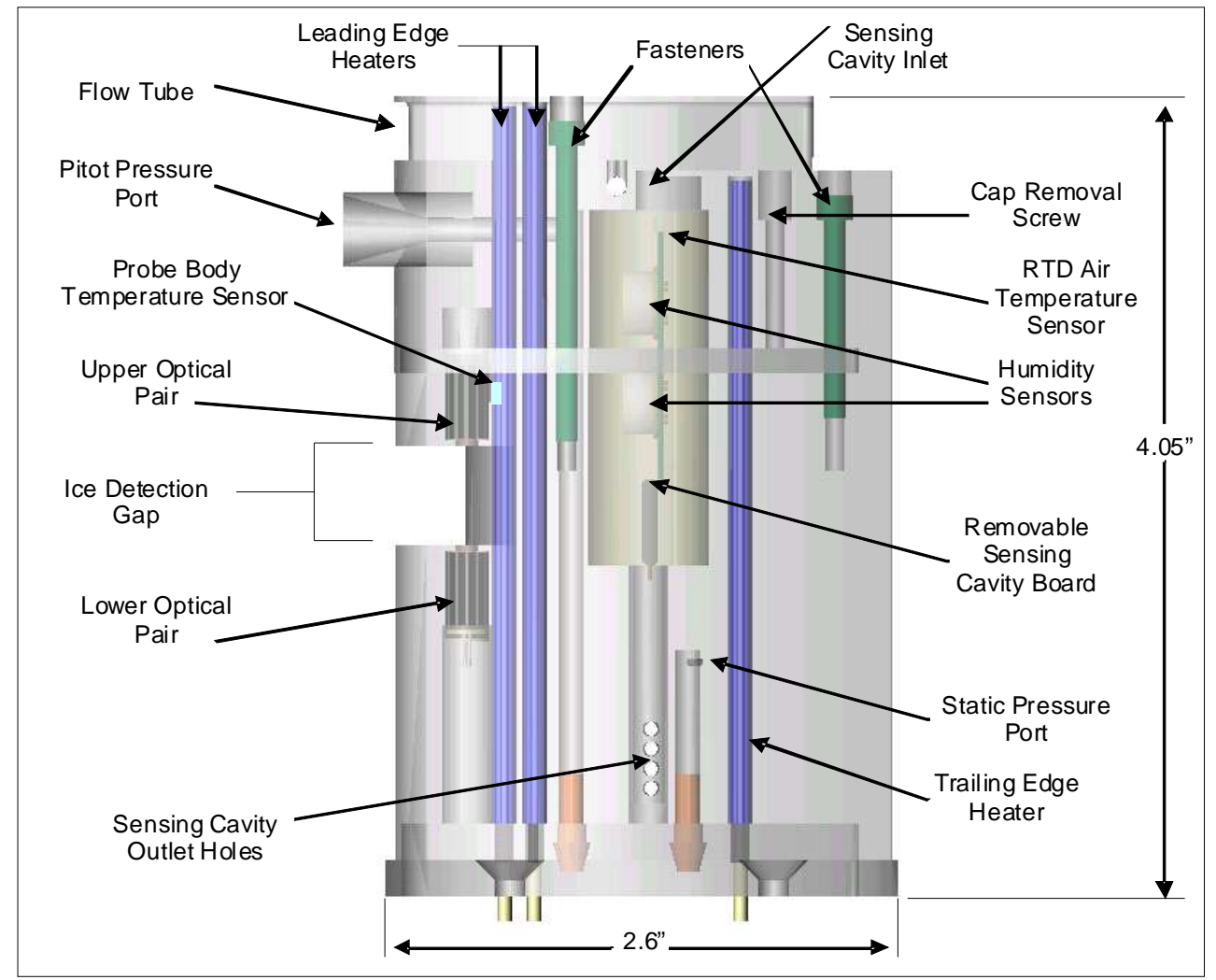

Figure A-1. TAMDAR Probe Detail

\begin{tabular}{|c|c|c|c|c|c|}
\hline Parameter & Range & Accuracy & Resolution & $\begin{array}{l}\text { Latency (See } \\
\text { Note 1) }\end{array}$ & Comments \\
\hline Pressure & $10-101 \mathrm{kPa}$ & $2 \mathrm{hPa}$ & $0.05 \mathrm{hPa}$ & $10 \mathrm{sec}$ & See Note2. \\
\hline Temperature & -70 to $+65^{\circ} \mathrm{C}$ & $\pm 1^{\circ} \mathrm{C}$ & $0.1^{\circ} \mathrm{C}$ & $10 \mathrm{sec}$ & \\
\hline Humidity & $\begin{array}{l}0 \text { to } 100 \% \\
\mathrm{RH}\end{array}$ & $\begin{array}{l} \pm 5 \% \text { (typical) } \\
\pm 10 \% \text { (typical) }\end{array}$ & $\begin{array}{l}1 \%(\mathrm{RH}>10 \%) \\
0.1 \%(\mathrm{RH}<10 \%)\end{array}$ & $10 \mathrm{sec}$ & $\begin{array}{l}\text { Below Mach } 0.4 \\
\text { Mach } 0.4-0.6 \\
\text { (RH from } 2 \text { separate } \\
\text { sensors is reported) }\end{array}$ \\
\hline Heading & $0-360^{\circ}$ & $\pm 3^{\circ}$ & $0.1^{\circ}$ & $10 \mathrm{sec}$ & $@<30^{\circ}$ pitch \& roll \\
\hline $\begin{array}{l}\text { Ice } \\
\text { Detection }\end{array}$ & & 0.020 inch & & & \\
\hline
\end{tabular}

Table A-1. Measured parameters 


\begin{tabular}{|c|c|c|c|c|c|}
\hline Parameter & Range & Accuracy & Resolution & Latency & Comments \\
\hline Pressure Altitude & $0-25,000 \mathrm{ft}$. & \pm 150 feet & 10 feet & $10 \mathrm{sec}$ & See Note 2 \\
\hline Pressure Altitude & $25,000-50,000 \mathrm{ft}$. & \pm 250 feet & 10 feet & $10 \mathrm{sec}$ & See Note 2 \\
\hline $\begin{array}{l}\text { Indicated } \\
\text { Airspeed }\end{array}$ & $70-270$ knots & \pm 3 knots & $1 \mathrm{knot}$ & $10 \mathrm{sec}$ & See Note 2 \\
\hline True Airspeed & $70-450$ knots & \pm 4 knots & $1 \mathrm{knot}$ & $10 \mathrm{sec}$ & See Note 2 \\
\hline $\begin{array}{l}\text { Turbulence (eddy } \\
\text { dissipation rate-- } \\
\left.\in^{1 / 3}\right) ; \text { Peak and } \\
\text { Median }\end{array}$ & $0-1 \mathrm{~m}^{2 / 3} \mathrm{sec}^{-1}$ & & & $3 \mathrm{sec}$ & $\begin{array}{l}\text { See Note } 3 . \\
\text { Reported as single encoded } \\
\text { character (see TAMDAR } \\
\text { Downlink Data Format). }\end{array}$ \\
\hline Winds Aloft & & $\begin{array}{l} \pm 6 \text { knots } \\
\text { vector } \\
\text { magnitude } \\
\text { error }\end{array}$ & $\begin{array}{l}1 \text { knot, } \\
1 \text { deg }\end{array}$ & $10 \mathrm{sec}$ & $\begin{array}{l}\text { See Note } 4 . \\
\text { Accuracy depends on relative } \\
\text { magnitude and direction of } \\
\text { vectors. }\end{array}$ \\
\hline
\end{tabular}

Table A-2. Derived parameters

Notes:

1. 10-second latency is caused by digital filtering of the data as recommended in the AMDAR Reference Manual, 2003.

2. Accuracy specified for angles of attack less than $+/-8^{\circ}$ from nominal except for winds aloft whose accuracy depends on the heading sensor used.

3. Turbulence determination: calculation of eddy dissipation rate in accordance with MacReady. Atmospheric Calculated from 32 point DFT of TAS (3 sec block).

4. Winds aloft calculation will require use of GPS and magnetic heading. 